\title{
Materials, properties, manufacturing methods and cutting performance of innovative ceramic cutting tools - a review
}

\author{
Sergey N. Grigoriev ${ }^{1}$, Sergey V. Fedorov ${ }^{1, *}$, and Khaled Hamdy ${ }^{1,2}$ \\ ${ }^{1}$ Moscow State University of Technology (MSUT) "STANKIN", Moscow 127055, Russia \\ 2 Production and Machine Design Department, Faculty of Engineering, Minia University, Minia 61519, Egypt
}

Received: 21 March 2019 / Accepted: 28 April 2019

\begin{abstract}
For mechanical machining the quality of cutting-tool materials is one of the most significant issues that need to be addressed. Enhancement of cutting tool performance may be achieved through the use of modern composition ceramic cutting tools This may be enabled through surface treatment, and also hot pressing and spark plasma sintering - the two main processes used for manufacturing such tools. In this article the advantages and disadvantages of the technologies and processes involved are analyzed and compared to identify the most appropriate methods for creating ceramic cutting-tools. In parallel the latest improvements in ceramic cutting-tool materials are reviewed. The paper shows that the choice of ceramic cutting tools is a quite complex process with a number of important factors to be taken into account.
\end{abstract}

Keywords: Ceramic cutting tool / tool performance / tool life / spark plasma sintering / hot pressing

\section{Introduction}

To remain competitive modern manufacturing companies must ensure they utilize the latest and most efficient technologies [1]. Machining processes are one of the effective ways of producing products with high accuracy and suitable surface roughness [2]. More complex geometries of products exhibit new challenging production situations for machining processes of cutting tools [3].

The mechanical properties especially hardness of product materials are being developed and enhanced. All traditional or conventional ways of machining processes such as drilling, turning and milling depend on the hardness of the cutting tool being higher than the hardness of the material being cut. The cutting instruments of several machining processes suffer from a short lifetime due to gradually reducing hardness and subsequently the cost of machining increases [4-7].

Cutting tool development is important for enhancing the mechanical properties especially in high-speed machining with a long duration. However the production of its cutting tools faces challenges for many reasons. Firstly the material must meet mechanical property requirements. Secondly conventional sintering methods are restricted with the number of materials and the time needed to achieve the sintering cycle, which are reflected in the

\footnotetext{
* e-mail: sv.fedorov@icloud.com
}

product cost. These are significant constraints in the manufacture of these tools [8]. Additionally, cutting tools materials must be able to resist extreme cutting conditions such as high temperature and friction between the workpiece and the cutting tool surface. Therefore cutting tool materials should exhibit a variety of properties to meet these requirements [9]. These are highlighted below.

- Mechanical properties:

- High hardness at elevated temperature.

- High deformation resistance to prevent plastic deformation at cutting edge.

- High stiffness to maintain accuracy.

- High fatigue resistance to resist maximum mechanical load.

- High fracture toughness.

- Thermal properties:

- High thermal conductivity to transfer the temperature away from the cutting edge.

- High thermal shock resistance.

- Chemical composition being stable.

- Tribological properties:

- Wear resistance.

- Adequate lubricity to prevent build-up on the cutting edge.

Figure 1 shows the comparison graphically between the ceramic, cermets and tungsten carbide tool and it illustrates differences in the mechanical properties between them. 


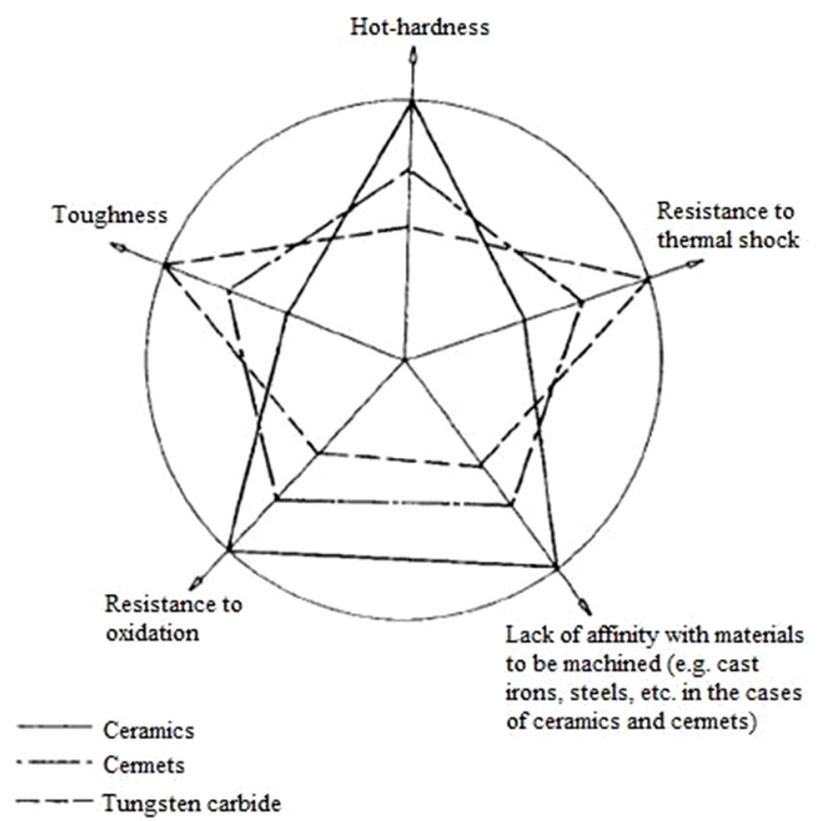

Fig. 1. Mechanical properties of ceramic, cermets and tungsten carbide [10].

The cutting tool characteristics are extremely important in the process of machining. Design, geometry, type, tool life, and material of the cutting tool are important parameters which affect directly on the cost and the quality of the product. The development of new alloys is associated with the development of cutting tool materials. Ceramic cutting tools exhibit high hardness and good performance in wear resistance, so that they play an important role, for example, in the high-speed machining process of super alloys [11].

From Figure 2, it may be concluded that ceramics are hard and can withstand a temperature of machining more than a temperature $1600^{\circ} \mathrm{C}$ without any chemical decomposition [12]. Ceramics can take far more heat than carbides because they soften in the range of $2200^{\circ} \mathrm{C}$ versus about $870^{\circ} \mathrm{C}$ for carbide tools [9]. Therefore the ceramic cutting tools are recommended for high-speed machining for hard to cut material in case of dry machining conditions.

Cutting ceramics is one of the most promising tool materials; the share of which in metal processing is increasing. Depending on the type of material to be processed and the type of machining, the potential of a metal-cutting ceramic tool, one-piece or equipped with replaceable polyhedral plates, grows. An interest in ceramic cutting materials is due to their significant heat and wears resistance compared to high-speed steels and hard alloys. Through the use of such materials the cutting speed can be dramatically increased (1.5-8 times compared to carbide tools) and reduce the processing time reduced by $2-3$ times. This material therefore is principally aimed at high-speed, high-energy machining (in turning of super alloys it provides $2-5$ times higher performance than that of hard alloy).

Figure 3 shows the requirements for manufacturing cutting tools from ceramic material in a simplified view.

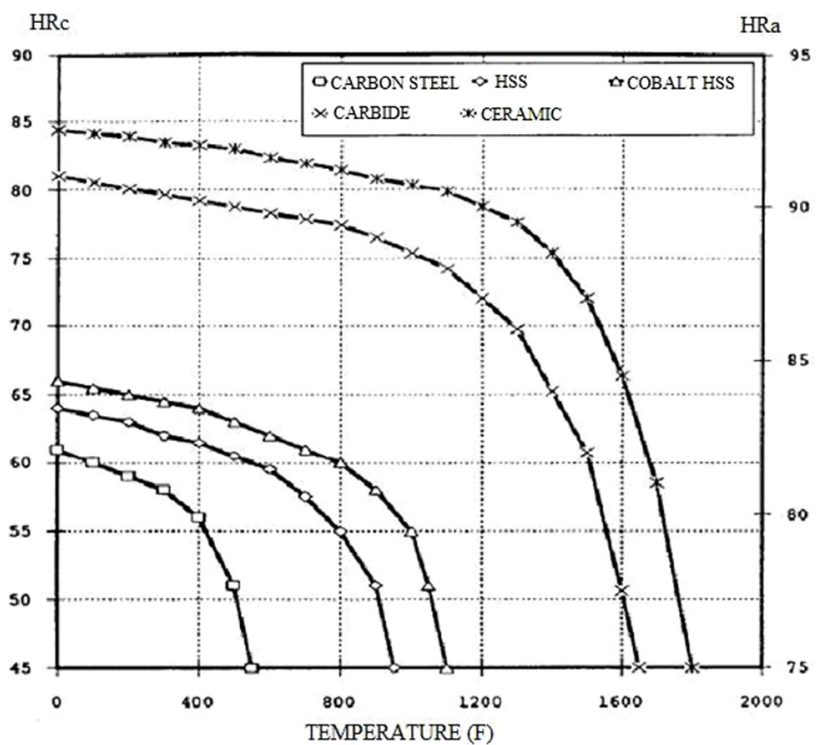

Fig. 2. Relationship between the temperature and hardness for various cutting tool materials [13].

Cutting tools in general face challenges and every element needs to be enhanced. The development of ceramic cutting tools has the potential to solve these problems.

\section{Ceramic cutting tool materials}

Ceramic cutting tool materials are created for machining cast irons and super-alloys materials in addition to finishing hard-to-cut materials [9]. Such tools have unique mechanical properties, and they have high hardness, corrosion, and adhesion wear resistance compared to carbide cutting tools $[14,15]$ They also have other distinct advantages and disadvantages such as [16]:

- High strength when machining hard to cut material especially in light machining.

- Show extremely high resistance to cratering and abrasive wear.

- The ability of high cutting speed.

On the other hand, the brittleness and low value of transverse rupture strength of the ceramic tools creates some limitations on its use [16]. Early ceramic cutting tools also suffered from low toughness and low resistance to mechanical and thermal shock because they suffered from low thermal conductivity [17]. Subsequently, with highspeed machining those defects became slightly more pronounced and in order to decrease the cycle time a restricted average of depth of cut was required [18]. Thus ceramic cutting tools also face problems in the case of interrupted cutting. In order to overcome these weaknesses the problems have been addressed by a number of researchers and their results are discussed in this paper.

The color of the ceramic usually is black or gray in the case of manufacturing by a hot pressing technique and a white color in the case of a cooled pressed technique. Cold pressed ceramic is slightly harder than hot pressed ceramic [16]. 


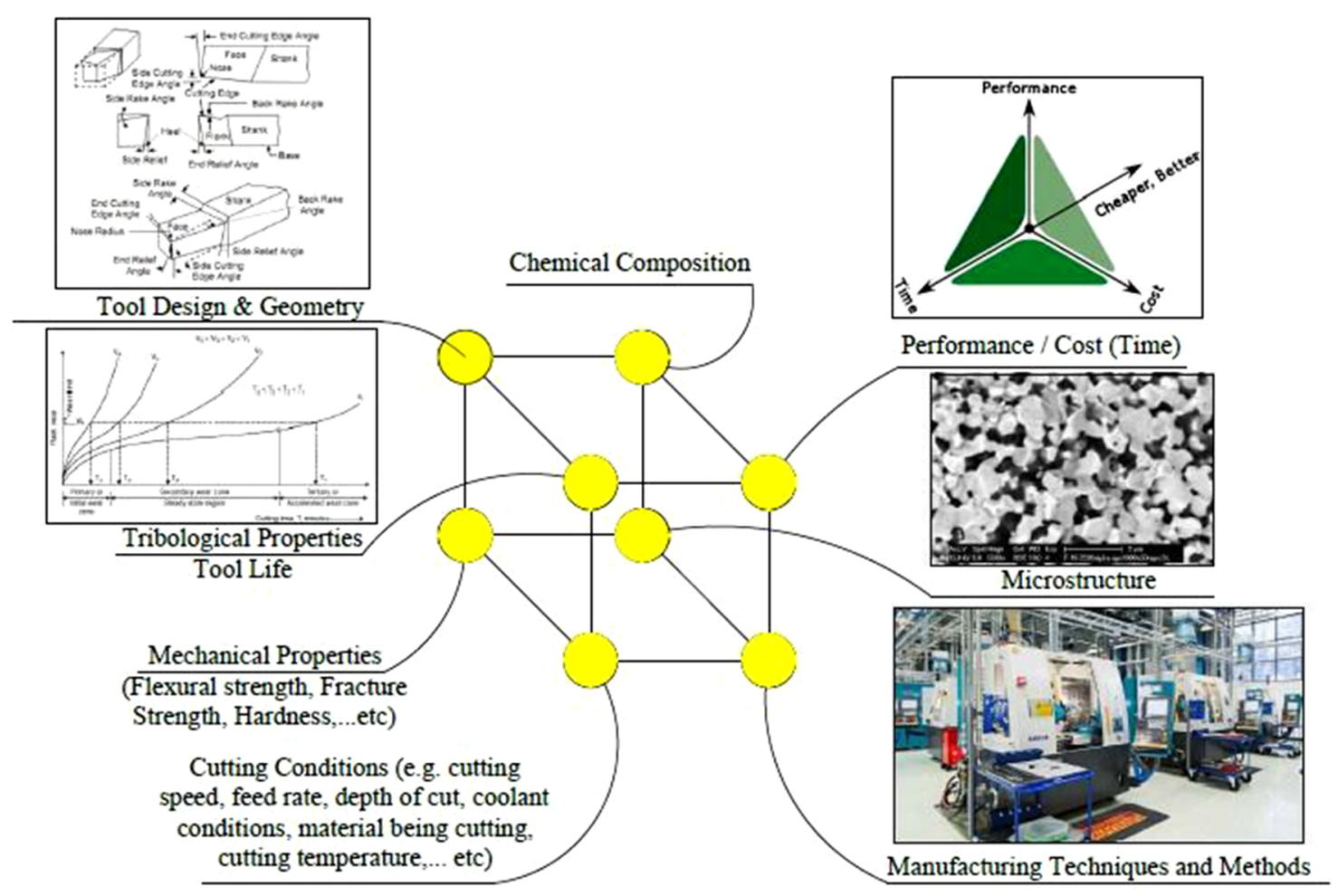

Fig. 3. Requirements for ceramic cutting tools.

Ceramic cutting tools can be indexed into four mains families as follows [17]:

- $\mathrm{Al}_{2} \mathrm{O}_{3}$-based ceramics.

- $\mathrm{Si}_{3} \mathrm{~N}_{4}$-based ceramics.

- Sialon-based ceramics.

- Cermet tool materials.

The main types are based on aluminum oxide $\left(\mathrm{Al}_{2} \mathrm{O}_{3}\right)$ and silicon nitride $\left(\mathrm{Si}_{3} \mathrm{~N}_{4}\right)$ [9]. In this regard, there are several additions to ceramic cutting tools such as alumina tools which contain titanium, magnesium, chromium or zirconium oxides [12]. Ceramic also is the main composition of cermet. The producing of cermets is similar to the production of ceramics by a hot-pressed technique. The composition of cermets is approximately $70 \%$ ceramic and $30 \%$ titanium carbide, and they are pressed into bullets with high pressure and temperature. The material is processed to the required shape for the cutting tool after sintering. Zirconium oxide is added to the ceramic alloy with a rate of $15 \%$ of the total composition to increase the strength of the ceramic [16]. Aluminum oxide, commonly referred to as alumina, possesses strong ionic interatomic bonding giving rise to its desirable material characteristics [9].

\subsection{Aluminum oxide type ceramics}

Many types of ceramics depend on aluminum oxide $\mathrm{Al}_{2} \mathrm{O}_{3}$ as the main base for machining ultra-high-strength steels [19]. Alumina materials have unique properties and high hardness. Therefore they may be used for producing cutting tool materials. However, the brittleness and poor damage tolerance have limited the application of alumina ceramics [20,21]. Nevertheless, alumina-based ceramic tools have unique mechanical and chemical properties, especially at high temperatures, such as high wear resistance, high hardness and relatively low chemical reactivity with steels and many other materials.

Commercially available cutting tool materials belonging to the group of carboxide ceramics consist of aluminum oxide with additions of $30-40 \%$ titanium carbide and titanium nitride. The dispersion of these hard particles increases the hardness for temperatures up to $800^{\circ} \mathrm{C}$ when compared to oxide ceramics. Simultaneously, the fracture toughness and bending strength are improved through crack impediment, crack deflection or crack branching caused by the dispersed hard particles. The higher hardness in combination with the higher toughness increases the resistance to abrasive and adhesive ear considerably. The lower thermal expansion and higher thermal conductivity of the composite improves the thermal shock resistance and thermal shock cycling capabilities when compared to oxide ceramics. At temperatures exceeding $800^{\circ} \mathrm{C}$, the titanium carbide and titanium nitride particles oxidize and begin to lose their reinforcing properties. The composite weakens and this phenomenon must be taken into consideration when selecting cutting conditions, such as cutting speed, depth of cut and feed-rate [22].

Ceramic aluminum oxide can be found in the main two types as following [23]:

- Aluminum oxide $\mathrm{Al}_{2} \mathrm{O}_{3}$, sometimes mixed with zirconium oxide, $\mathrm{Al}_{2} \mathrm{O}_{3} / \mathrm{ZrO}_{2}$. In color, these tools are varied 
Table 1. Comparison between the oxide ceramic $\mathrm{Al}_{2} \mathrm{O}_{3} /$ $\mathrm{ZrO}_{2}$ and $\mathrm{Al}_{2} \mathrm{O}_{3} / \mathrm{TiC}$ composite [22].

\begin{tabular}{lll}
\hline Cutting materials & $\begin{array}{l}\text { Oxide ceramic } \\
\mathrm{Al}_{2} \mathrm{O}_{3}+\mathrm{ZrO}_{2}\end{array}$ & $\begin{array}{l}\mathrm{Al}_{2} \mathrm{O}_{3} / \mathrm{TiC} \\
\text { composite }\end{array}$ \\
\hline $\begin{array}{l}\text { Hardness (Vickers) } \\
\begin{array}{l}\text { Modulus of elasticity } \\
\left(\mathrm{KN} / \mathrm{mm}^{2}\right)\end{array}\end{array}$ & 2000 & 2200 \\
$\begin{array}{l}\text { Bending strength } \\
\left(\mathrm{N} / \mathrm{mm}^{2}\right)\end{array}$ & 390 & 400 \\
$\begin{array}{l}\text { Fracture toughness } \\
\left(\mathrm{mN} / \mathrm{mm}^{2}\right)\end{array}$ & 4.5 & 600 \\
$\begin{array}{l}\text { Coefficient of thermal } \\
\text { expansion }\left(10^{-6} \mathrm{~K}^{-1}\right)\end{array}$ & 7.5 & 5.4 \\
$\begin{array}{l}\text { Thermal conductivity } \\
\left(\mathrm{W} \mathrm{m} \mathrm{m}^{-1} \mathrm{~K}^{-1}\right)\end{array}$ & 30 & 7.0 \\
\hline
\end{tabular}

from yellow to gray/white. The tools are hardened for phase transformation, have high chemical inertness, resistance to wear and thermal deformation. They are used for continuous fine cutting (semi-finishing and finishing) at relatively low feed rates. Typical applications include turning and hard-to-machine carbon steels, alloy steels, tool steels $(<38 \mathrm{Rc})$ and gray cast iron or ductile cast iron $(<300 \mathrm{BHN})$ at speeds up to $1000 \mathrm{~m} / \mathrm{min}$. - Alumina-titanium carbide composites $\mathrm{Al}_{2} \mathrm{O}_{3} / \mathrm{TiC}$, containing $30-40 \%$ TiC. This black material has a higher transverse rupture strength, thermal shock resistance and hardness than $\mathrm{Al}_{2} \mathrm{O}_{3}$, but at the same time, it has a relatively low resistance to fracture. It is for continuous cutting on alloy steels, chilled and malleable cast irons, hardened ferrous materials (35-65Rc) and exotic alloys. Coated $\mathrm{Al}_{2} \mathrm{O}_{3} /$ TiC tools are used for finishing turning hardened steels and cast irons. All materials based on aluminum oxide $\left(\mathrm{Al}_{2} \mathrm{O}_{3}, \mathrm{Al}_{2} \mathrm{O}_{3} / \mathrm{ZrO}_{2}, \mathrm{Al}_{2} \mathrm{O}_{3} / \mathrm{TiC}\right)$ tend to crack and wear a notch when machining steel. Also, chemically induced wear may occur depending on the cutting temperature and the environment (air, humidity, coolant). $\mathrm{Al}_{2} \mathrm{O}_{3}$ based tools are not suitable for machining aluminum alloys and titanium alloys due to their strong chemical affinity with these materials. They replace carbide inserts $\mathrm{P} 01-\mathrm{P} 05$ or $\mathrm{C} 8$.

Hence Table 1 is a summary of the comparison between the different compositions of ceramic aluminum oxide in the category of the mechanical properties. Adding of TiC particles into $\mathrm{Al}_{2} \mathrm{O}_{3} / \mathrm{SiC}_{\mathrm{w}}$ ceramic materials could improve the electrical conductivity and mechanical properties of composite materials [11]. Silicon carbide whiskers added to an $\mathrm{Al}_{2} \mathrm{O}_{3}$ matrix in a random orientation produces a ceramic tool material with very high toughness [22]. SiC whiskers enhance the hardness and elasticity modulus of $\mathrm{Al}_{2} \mathrm{O}_{3}$ ceramic materials, but they limit the flexural strength and fracture toughness as compared with SiAlON ceramic materials. By incorporating particles or whiskers into the matrix it is observed that clear improvements are made in mechanical properties of monolithic ceramics [11].

The $\mathrm{Al}_{2} \mathrm{O}_{3}$ based composite ceramic tool materials have advantages in the field of high-speed machining compared to the traditional high-speed steel and cemented carbide cutting tools, due to the high hardness, excellent wear and corrosion resistance of ceramics as well as the low affinity with metal. They can also machine hardened steel, nickelbased alloys, and other difficult-to-cut materials, so ceramic tool materials are considered as the most promising and competitive tool materials [24].

Several types of chemical wear of ceramic tools are recognized: reactions of the workpiece material or environment with the alumina oxide matrix and reactions with strengthening phases ( $\mathrm{TiC}, \mathrm{SiC}, \mathrm{Si}_{3} \mathrm{~N}_{4}, \mathrm{TiB}_{2}$ ). Alumina cutting tools when machining steels are known to react with the formation of iron-based spinels of $\mathrm{Fe}_{2} \mathrm{O}_{3} /$ $\mathrm{Al}_{2} \mathrm{O}_{3}$ [25].

During the past two decades, much effort has been made to improve the strength and toughness of ceramic materials. Several useful methods have been proposed some of which are crack-surface bridging, particle dispersion of different phases in a matrix, fiber reinforced composites, macroscopic crack deflection, and phase transformation induced toughening as revealed by zirconia [26].

Adding nano-particles is one of the common strengthening methods and has been proven to be effective in improving the mechanical properties of materials [27]. Mechanical properties affect directly on the performance of cutting tool thus Cheng et al. [21] investigated by a traditionally way the mechanical properties for two types of ceramic cutting tool material $\mathrm{Al}_{2} \mathrm{O}_{3} / \mathrm{TiC} \mu$ and $\mathrm{Al}_{2} \mathrm{O}_{3} /$ $\mathrm{TiC} \mu / \mathrm{TiCn}$ in room temperature and elevated temperature with range from $\left(600{ }^{\circ} \mathrm{C}\right.$ to $\left.1100{ }^{\circ} \mathrm{C}\right)$ concerning the effect of nano- $\mathrm{TiC}$ on the mechanical properties for those cutting tools. They demonstrated that nano-TiC enhanced the transgranular fracture during fracture. Thus the mechanical properties are enhanced. They also found that the existence of $\mathrm{TiC}$ at high temperature affects negatively on the mechanical properties because of the softening of the grain boundary. The oxidation of TiC also has a negative effect on the mechanical properties and creates $\mathrm{TiO}_{2}$ on the surface layer where cracks appeared. Also Dong et al. [26] studied the mechanical properties and they were interested in hardness, fracture toughness and flexural strength for $\mathrm{Al}_{2} \mathrm{O}_{3}$ composites with 1-20 wt.\% micro-sized $\mathrm{SiC}$ particles which were made by hot pressing. They showed that the fracture strength and fracture toughness were enhanced in comparison with monolithic $\mathrm{Al}_{2} \mathrm{O}_{3}$.

Alumina reinforced with $\mathrm{SiC}$ whiskers is the toughest and most resistant to thermal shock of the $\mathrm{Al}_{2} \mathrm{O}_{3}$-based ceramics. $\mathrm{SiC}$ whiskers used for reinforcement are discontinuous, rod- or needle-shaped fibers in size range of $0.1-1 \mu \mathrm{m}$ in diameter and $5-100 \mu \mathrm{m}$ in length. The incorporation of $\mathrm{SiC}$ whiskers into the ceramic matrix results in the increase of strength, fracture toughness, thermal conductivity, thermal shock resistance, and high temperature creep resistance. Because they are nearly single crystals, the whiskers typically have very high tensile strength about $7 \mathrm{GPa}$ and elastic Young's modulus values up to $550 \mathrm{GPa}$. Unlike other such materials, these materials 
can be run with coolant. High-speed finishing of nickel/ cobalt-based super-alloys is a typical application for whisker-reinforced ceramic cutting tools [28]. In this regard, Ko et al. [29] studied hardness, fracture toughness and tool life of $\mathrm{Al}_{2} \mathrm{O}_{3} / \mathrm{SiC}$ composites cutting tool material with 30 wt. $\%$ SiC particles produced by hot pressing.

Meanwhile, Bushlya et al. [28] concerned with the characterization of wear mechanism of $\mathrm{SiC}$ Whiskers reinforced alumina in turning aged Alloy 718, under different machining conditions and with dry or coolant. Notch wear consists of two types, first wear is the depth of cut notch, and another one is the notch which is located outside the chip area. The second one is found by adhesion wear and associated with adverse chip flow conditions. Spread of $\mathrm{Ni}, \mathrm{Fe}$, and $\mathrm{Cr}$ into $\mathrm{SiC}$ whiskers was found to degrade them and facilitate adhesion. The tool deterioration is accelerated by the plastic deformation and cracking on the tool rake.

Moreover, Xuefei et al. [30] created a new $\mathrm{Al}_{2} \mathrm{O}_{3}$ based ceramic tool material, and they proposed a new tool material synergistically toughened by $\mathrm{SiC}$ whiskers and nano-particles, and of course they studied the mechanical properties for the tool at room temperature and high elevated temperature range from $700^{\circ} \mathrm{C}$ to $1200^{\circ} \mathrm{C}$. It is demonstrated that flexural strength increased in initial increasing temperature but with subsequent increasing of temperature the flexural subsequently decreased. The degradation of the mechanical properties at high temperature occurred because of the oxidation of $\mathrm{SiC}$ and the decrease of its elasticity modulus. For fracture toughness of the proposed material this decreased for temperatures from $700^{\circ} \mathrm{C}$ to $1100^{\circ} \mathrm{C}$ but it increased at the temperature of $1200^{\circ} \mathrm{C}$ with significant plasticity. The degradation of mechanical properties at elevated temperatures is related to oxidation of $\mathrm{SiC}$ and a decrease of its elasticity modulus, but at high temperature, the healing of micro-cracks and defects improve the mechanical properties.

$\mathrm{Al}_{2} \mathrm{O}_{3} / \mathrm{TiC}$ is acceptable for most machining situations where ceramics are applicable. It is an excellent material for turning tool steels as hard as 60-63 Rc and producing surface finish values of less than $1 \mu \mathrm{m}$. This versatile ceramic material also has excellent thermal stability and is capable of cutting dry or with a water-base cutting fluid [22]. According to that, Li et al. [31] not only studied the mechanical properties but also experimentally and theoretically they studied the effect of reinforcing multi-layer (MLG) on the flexural strength and fracture toughness of $\mathrm{Al}_{2} \mathrm{O}_{3} / \mathrm{TiC}$ ceramic tool material. They also analyzed the crack path by using the fractural method to obtain the proper reinforced mechanism. They concluded that in the case of addition of MLG by $0.2 \mathrm{wt} . \%$, the average flexural toughness changed from $4.98 \mathrm{MPa} \mathrm{m}^{1 / 2}$ for $\mathrm{Al}_{2} \mathrm{O}_{3} / \mathrm{TiC}$ to $6.14 \mathrm{MPa} \mathrm{m}^{1 / 2}$, and flexural strength is enhanced.

Machining of ultra-high-strength steels is achieved by using $\mathrm{Al}_{2} \mathrm{O}_{3}$ based cemented materials and coated cemented carbide. Wang et al. [32] studied micro-structure and mechanical properties of proposed cutting tool material $\mathrm{Al}_{2} \mathrm{O}_{3} / \mathrm{TiC} / \mathrm{TiN}$ and the machining conditions on ultra-high steel and the wear mechanism in comparison with $\mathrm{Al}_{2} \mathrm{O}_{3} / \mathrm{TiC}$ ceramic tools. The best result is with a sintering temperature of $1650^{\circ} \mathrm{C}$, holding time $15 \mathrm{~min}$ and sintering pressure $35 \mathrm{MPa}$. Wear which accrued in the tool is abrasion and adhesive wear but the proposed tool is a good substitution for a ceramic cutting tool.

Yin et al. [24] reinforced the $\mathrm{Al}_{2} \mathrm{O}_{3}$-based composite ceramic tool with micro-scale and nano-scale $\mathrm{TiC}$ particles by hot pressing with different percentages of cobalt. They also discussed the relationship between the mechanical properties and microstructure. Poor relative density is combined with low content of the cobalt, but excess cobalt causes micro-cracks at grain boundaries. The existence of inter-phase cobalt could effectively decrease the stress concentration and value of the tensile strength of the $\mathrm{Al}_{2} \mathrm{O}_{3}$ matrix. Both the micro-scale and the nano-scale $\mathrm{TiC}$ particles contributed to the improvement of flexural strength and fracture toughness of the composite. Liu et al. [33] studied reinforcing alumina ceramic composites with graphene platelets (GPLs) by spark plasma sintering, and then they became interested with the effect of GPLs on the microstructure and mechanical properties of the $\mathrm{Al}_{2} \mathrm{O}_{3}$ based ceramic material. It was demonstrated that the flexural strength and fracture toughness of prepared ceramic is higher than monolithic $\mathrm{Al}_{2} \mathrm{O}_{3}$ increasing by $30 \%$ for flexural strength and $27 \%$ for fracture toughness. An et al. [34] also worked on the alumina and produced alumina CNT composites to investigate the effect of carbon nano-tube addition on the mechanical and tribological properties by hot pressing. Besides the mechanical properties Smirnov et al. [35] studied other properties such as electro-discharge machinability and microstructure they were interested with compressive strength, elastic modulus, fracture toughness, fracture strength in bending of an $\mathrm{Al}_{2} \mathrm{O}_{3} / \mathrm{SiC} / \mathrm{TiC}$ composite cutting tool which is produced by hot pressing sintering. The fracture strength and creep resistance of $\mathrm{Al}_{2} \mathrm{O}_{3}$-based ceramics may be increased by adding $5 \%$ nanosized $\mathrm{SiC}$ particles.

However, when comparing with silicon nitride the strength of $\mathrm{Al}_{2} \mathrm{O}_{3}$ composites are still lower [8]. In the next section, silicon nitride type ceramics are discussed.

\subsection{Silicon nitride based ceramics}

Silicon nitride $\mathrm{Si}_{3} \mathrm{~N}_{4}$-based ceramics are used for the material of cutting tools that came into use during the 1980 and are superior to $\mathrm{Al}_{2} \mathrm{O}_{3}$-based ceramics when considering some factors. For example, the flexural strength of silicon nitride ceramics can be as high as 700-1100 MPa. Silicon nitride ceramic cutting tools have excellent thermal shock resistance, fracture toughness, and also exhibit stable cutting performance as they are resistant to crack formation [36].

There are several types of silicon nitride $\mathrm{Si}_{3} \mathrm{~N}_{4}$ such as reaction-bonded silicon nitride $\left(\mathrm{Si}_{3} \mathrm{~N}_{4} \mathrm{RB}\right)$, hot pressed silicon nitride $\left(\mathrm{Si}_{3} \mathrm{~N}_{4} \mathrm{HIP}\right)$, sintered reaction bonded $\mathrm{Si}_{3} \mathrm{~N}_{4}$, sintered $\mathrm{Si}_{3} \mathrm{~N}_{4}$ and $\mathrm{SiAlON}$, all of which are gray. $\mathrm{Si}_{3} \mathrm{~N}_{4} \mathrm{RB}$ and $\mathrm{HIP}$ are combinations of $\mathrm{Si}_{3} \mathrm{~N}_{4}$ with yttrium oxide, $\mathrm{Al}_{2} \mathrm{O}_{3}$, and $\mathrm{TiC}[23]$.

In the previous few decades, the use of silicon nitride increased because of its good wear resistance. It also has high-temperature strength and hardness with good toughness and perfect thermal shock resistance [37]. However, it is difficult to sinter silicon nitride without 
additives because it has low diffusion at sintering temperature due to the thermal decomposition at high temperature. Therefore research has been carried out on different sintering additives in $\mathrm{Si}_{3} \mathrm{~N}_{4}$ to provide density during the liquid-phase mechanism of sintering [38].

SiAlON is a ceramic alloy containing silicon, aluminum, oxygen, and nitrogen, developed to be simpler to fabricate into tools than monolithic silicon nitride. Compared to the materials in the first two categories, these tough ceramics exhibit superior wear and notch resistance, high red hardness, and resistance to thermal shock; tools made from them are consequently more reliable. The $\mathrm{Si}_{3} \mathrm{~N}_{4}$ tools are extremely wear resistant when used to machine cast and malleable irons but are subject to excessive temperatureactivated wear when machining steels and other ductile materials at high speeds. SiAlON, conversely, has been applied successfully on both gray cast iron and steel at high speeds. SiAlON is more chemically stable than $\mathrm{Si}_{3} \mathrm{~N}_{4}$ but not quite as resistant to thermal shock. The $\mathrm{Si}_{3} \mathrm{~N}_{4}$ is commonly used for machining cast iron at speeds up to $1200 \mathrm{~m} / \mathrm{min}$; for this working material, the speed limit for plain WC tooling is $100 \mathrm{~m} / \mathrm{min}$. More chemically stable grades, especially sintered grades, are also commonly used to machine nickel-based super-alloys for aerospace and corrosion components, as well as hard steels for a variety of uses. They are not generally used for aluminum alloys due to the high solubility of silicon in aluminum. They substitute for K01 to K05 or C4 carbide inserts [23].

Cutting tool materials based on silicon nitride include fully dense $\mathrm{Si}_{3} \mathrm{~N}_{4}$ and SiAlON materials, which are solid solutions of alumina in $\mathrm{Si}_{3} \mathrm{~N}_{4}$. Fully dense $\mathrm{Si}_{3} \mathrm{~N}_{4}$ can have fracture toughness nearly as high as cemented carbides, high strength and a low coefficient of thermal expansion, which result in good thermal shock resistance. The siliconbased ceramics are excellent in maintaining hot hardness at temperatures higher than those suitable for cemented carbide and are tougher than aluminum-based ceramics. Tools made with this material are excellent for turning grey cast iron at cutting speeds over $400 \mathrm{~m} / \mathrm{min}$, and are also used for milling and other interrupted operations on grey iron. Coolant can be used for turning applications. SiAlON is typically more chemically stable than $\mathrm{Si}_{3} \mathrm{~N}_{4}$ but are not quite as tough or resistant to thermal shock. They are mainly used in the rough turning of nickel-based superalloys [28].

Kvetkova et al. [39] proposed silicon nitride +1 wt. $\%$ graphene platelet composites by using different graphene platelets in addition to two processing routes, hot isostatic pressing and gas pressure sintering (GPS). They investigated the influence of processing route and graphene platelets addition on the fracture toughness. The matrix of the composites prepared by GPS consists of $\mathrm{Si}_{3} \mathrm{~N}_{4}$ grains with a smaller diameter in comparison to the composites prepared by hot isostatic pressing. The indentation fracture toughness of the composites differed around 6.1-9.9 $\mathrm{MPam}^{0.5}$, which is higher compared to the monolithic silicon nitride 6.5 and $6.3 \mathrm{MPa} \mathrm{m}^{0.5}$. The highest value of $\mathrm{K}_{1} \mathrm{C}$ was $9.9 \mathrm{MPam}^{0.5}$ in the case of composites reinforced by the smallest multilayer graphene nano-sheets set by hot isostatic pressing. The composites set by GPS exhibit lower fracture toughness, from 6.1 to $8.5 \mathrm{MPa} \mathrm{m}^{0.5}$.
Choi et al. [38] generally studied silicon nitride and tried to enhance the properties of the silicon nitride but they used another method by adding rare earth oxides such as $\left(\mathrm{La}_{2} \mathrm{O}_{3}, \mathrm{CeO}_{2}, \mathrm{Lu}_{2} \mathrm{O}_{3}, \mathrm{Dy}_{2} \mathrm{O}_{3}, \mathrm{Sm}_{2} \mathrm{O}_{3}, \mathrm{Nd}_{2} \mathrm{O}_{3}, \mathrm{Yb}_{2} \mathrm{O}_{3}\right.$, and $\mathrm{RuO}_{2}$ ) to $\mathrm{Si}_{3} \mathrm{~N}_{4}$ and studied the mechanical and thermal properties. They found that the flexural strength of silicon nitride of 5 vol. $\% \mathrm{Nd}_{2} \mathrm{O}_{3}, \mathrm{CeO}_{2}, \mathrm{Dy}_{2} \mathrm{O}_{3}$ and $\mathrm{Sm}_{2} \mathrm{O}_{3}$ has better values than nitride with $\mathrm{Lu}_{2} \mathrm{O}_{3}$ and $\mathrm{La}_{2} \mathrm{O}_{3}$ because they make a denser microstructure and smaller elongated grain. The thermal conductivity of silicon nitride with 6 vol. $\% \mathrm{RuO}_{2}$ was better than that with $\mathrm{Nd}_{2} \mathrm{O}_{3}, \mathrm{Sm}_{2} \mathrm{O}_{3}$ and $\mathrm{Dy}_{2} \mathrm{O}_{3}$ because of the addition of $\mathrm{RuO}_{2}$ depressed grain growth. Kumar et al. [40] did something similar by way of adding cerium oxide to alumina matrix composite to create an alumina ceramic composite. They observed that the created composite exhibits enhancements in mechanical properties such as the fracture toughness and hardness. Also, they also noted the increase in processing performance when using the proposed tool.

Tian et al. [41] worked on $\mathrm{Si}_{3} \mathrm{~N}_{4}$-based composite ceramic tool materials reinforced by nano-scale $\mathrm{Si}_{3} \mathrm{~N}_{4}$ and micro-scale $\mathrm{WC}$ and $\mathrm{TiC}$ fabricated by hot pressing and sintering technology. They studied flexural strength, fracture toughness, hardness, microstructure, and indentation cracks. They demonstrated that nano scale $\mathrm{Si}_{3} \mathrm{~N}_{4}$ accelerated the formation of elongated $\beta$-Si3N4 grains and contributed to enhanced mechanical properties.

Zheng et al. [42] produced $\mathrm{SiAlON} / \mathrm{Si}_{3} \mathrm{~N}_{4}$ nanocomposite ceramic tool materials with a five graded layered symmetrical distribution manufactured by a hot pressing technique. They measured the mechanical properties and residual stresses. They found that the best results were obtained with a $\mathrm{SiAlON} / \mathrm{Si}_{3} \mathrm{~N}_{4}$ ceramic tool material with ratio 0.3 and sintered at $1700-1750{ }^{\circ} \mathrm{C}$ under a pressure $35 \mathrm{MPa}$ of $60 \mathrm{~min}$, the characterization revealed a typical duplex distribution with small $\beta-\mathrm{Si}_{3} \mathrm{~N}_{4}$ grains in the matrix of large $\beta-\mathrm{Si}_{3} \mathrm{~N}_{4}$ grains. This duplex distribution improved the flexural strength and fracture toughness.

Tribological properties have an influence on tool performance. Therefore, Zheng et al. [43] created a graded structure in a $\mathrm{SiAlON} / \mathrm{Si}_{3} \mathrm{~N}_{4}$ ceramic tool material produced by the hot-pressing process. They compared the reliability and wear rate between the graded tool and a reference tool in machining Inconel 718 alloy and also investigated its surface roughness and the microstructure of chips. They demonstrated that a graded structure in the $\mathrm{SiAlON} / \mathrm{Si}_{3} \mathrm{~N}_{4}$ ceramic tool material could encourage the residual compressive stresses during the fabrication process. They also found that the tool life of the graded ceramic tool has a better tool life than a regular tool. This results from high wear resistance, and from synergistic strengthening and toughing motivated by tool structure. Compressive residual stresses are induced to enhance the wear resistance.

A short tool life increases the cost of the machining process. Therefore $\mathrm{Tu}$ et al. [44] investigated the tool life, cutting performance, wear mechanism, phase composition, and microstructure of two SiALON cutting inserts when dry turning gray cast iron. They found that the main phases of them were $\alpha$-SiALON and $\beta$-SiALON and one of the proposed tools contained more (A) $\alpha$-SiALON than 
another cutting tool (B). The tool life of sample B was longer than the other specimen at low speed however with increasing cutting speed, the tool life of sample A was almost equal the sample B. The types of wear were abrasive and adhesive wear.

Alloy Inconel 718 is defined as a heat resistant super alloy which can keep its mechanical strength at temperatures up to $650^{\circ} \mathrm{C}$ and fracture toughness down to $-40^{\circ} \mathrm{C}$. It exhibits corrosion resistance and high oxidation, but low thermal conductivity, adhesion behavior, abrasion wear and hardened microstructure cause a low tool life and a high wear rate [45]. Consequently Hao et al. [46] studied the tool wear morphology in machining Inconel 718 with selfreinforced SiAlON, and they demonstrated that abrasive wear and lamellar exfoliation are found when cutting speeds range from 50 to $200 \mathrm{~m} / \mathrm{min}$. It was discovered that the bond strength between $\beta$-SiAlON whiskers and the SiAlON matrix is reduced when cutting speed ranges from 350 to $500 \mathrm{~m} / \mathrm{min}$ causing a hole or groove. According to the wear mechanism with various machining conditions a model was created to minimize tool wear in milling Inconel 718 using a self-reinforced SiAlON ceramic tool.

\subsection{Ceramic as a composite material}

Reinforcing material to create composite material is one of the ways to enhance the properties of base material thus Cheng et al. [47] reinforced ceramic tool material $\mathrm{Al}_{2} \mathrm{O}_{3} /$ $\mathrm{TiC}$ type with graphene platelets (GPLs) by microwave sintering. They investigated not only mechanical properties but also the effects of GPLs contents on the microstructure, mechanical properties, and toughness mechanism of the $\mathrm{Al}_{2} \mathrm{O}_{3} / \mathrm{TiC} / \mathrm{GPLs}$ composite ceramic tool material. They deduced that the microstructure of the composite became finer with addition of GPLs and the optimum results were obtained with $0.2 \mathrm{wt} . \%$ GPLs. They compared the proposed tool with $\mathrm{Al}_{2} \mathrm{O}_{3} / \mathrm{TiC}$. As a result, the Vickers hardness is decreased by $12.7 \%$ but the fracture toughness increased by $67.3 \%$. According to Guo et al. [48], they discussed the influence of two kinds of $\beta-\mathrm{Si}_{3} \mathrm{~N}_{4}$ seed with the similar small diameter and different aspect ratio on $\mathrm{Lu}_{2} \mathrm{O}_{3}$ doped $\mathrm{Si}_{3} \mathrm{~N}_{4}$ ceramics. They showed that the addition of seeds with a low aspect ratio and small diameter produce a finer self-reinforced microstructure with elongated grains of small diameter. Thus they succeed in enhancing fracture toughness compared to the ceramics without seeds of similar diameter and high aspect ratio.

Inserting other components to the cutting tool material also enhance the performance thus Casto et al. [49] used three ceramic insert materials, Zirconium alumina $\left(\mathrm{Al}_{2} \mathrm{O}_{3} /\right.$ 7 vol.\% $\left.\mathrm{ZrO}_{2}\right)$, mixed based alumina $\left(\mathrm{Al}_{2} \mathrm{O}_{3} / \mathrm{TiN} / \mathrm{ZrO}_{2}\right)$ and alumina reinforced with $\mathrm{SiC}$ whiskers, $\left(\mathrm{Al}_{2} \mathrm{O}_{3} / \mathrm{SiC}_{\mathrm{w}}\right)$ in machining AISI 1040 steel at $3.9 \mathrm{~m} / \mathrm{s}$ also of commercial tool P10 insert (WC/ $\mathrm{TiC} / \mathrm{Co})$.

Lee et al. [50] deal with silicon nitride created by pressure-less sintering and they studied the effect of $\mathrm{SiO}_{2}$ content in the $\mathrm{Y}_{2} \mathrm{O}_{3} / \mathrm{Al}_{2} \mathrm{O}_{3}$ on the microstructure, mechanical properties and the dielectric properties of silicon nitride $\mathrm{Si}_{3} \mathrm{~N}_{4}$ ceramics. The content of total sintering additive was fixed at $8 \mathrm{wt} . \%$, and the amount of $\mathrm{SiO}_{2}$ was varied wt.\% to 7 , the flexural strength and the dielectric content is decreased with increasing $\mathrm{SiO}_{2}$ because of the residual porosity and the formation of $\mathrm{Si}_{2} \mathrm{~N}_{2} \mathrm{O}$ via reaction of $\mathrm{SiO}_{2}$ with $\mathrm{Si}_{3} \mathrm{~N}_{4}$.

Bitterlich et al. [51], created new ceramic alpha-betaSiAlON cutting tools prepared by gas pressure sintering and reinforced with $\mathrm{SiC}, \mathrm{WC}, \mathrm{MoSi}_{2}$ or $\mathrm{Ti}(\mathrm{CN})$ particles, they discussed the microstructure, mechanical properties and wear resistance. They observed that the best wear behavior was exhibited by the material with 10 vol.\% SiC. The material reinforced with $\mathrm{MoSi}_{2}$ showed a resistance to wear; however, it has low fracture toughness and low hardness.

Several techniques are enhancing the properties of the cutting tool material. One of those techniques is Cryogenics. It is an effective method to enhance mechanical as well as physical properties of the material by cooling down the tool to a temperature about $-196^{\circ} \mathrm{C}$ at a gradual rate, maintained at that temperature for a long time, about $24 \mathrm{~h}$, and then bring back to room temperature by heating [52]. Several steps must be done as following [53]: cooling slowly to a subzero temperature such as $-145^{\circ} \mathrm{C},-196^{\circ} \mathrm{C}$, soaking for a predetermined time from $4 \mathrm{~h}$ to $48 \mathrm{~h}$, heating slowly to the room temperature, tempering.

Gandotra et al. [52] attempt to estimate the effect of deep cryogenic treatment (DT) at $-190^{\circ} \mathrm{C}$ and shallow cryogenic treatment (ST) at $-110^{\circ} \mathrm{C}$ on the tool life of uncoated and coated $\mathrm{Al}_{2} \mathrm{O}_{3}$ and TiCN tools by investigating one of the flank wear types on the cutting tool life when turning high carbon high chrome. The results showed that DT tools act better than ST tool in case of uncoated tools but in the case of coated tool ST tools act better.

Concerning silicon nitride, Dusza et al. [54] prepared silicon nitride +1 wt.\% graphene platelet with using various graphene platelets (GPLs) with thickness $5-50 \mathrm{~nm}$ on the microstructure development and the fracture toughness of $\mathrm{Si}_{3} \mathrm{~N}_{4} / \mathrm{GPLs}$ composites. The fracture toughness was higher for all kinds in comparison with monolithic $\mathrm{Si}_{3} \mathrm{~N}_{4}$. The presence of graphene platelets increases the strength of ceramics by increasing resistance to cracking, crack deflection, branching and overlapping cracks. $\mathrm{Xu}$ et al. [55] investigated the rate of wear mechanism of an $\mathrm{Al}_{2} \mathrm{O}_{3} / \mathrm{Ti}(\mathrm{CN}) / \mathrm{SiC}$ multiphase composite ceramic tool material with dry machining hardened tool and cast iron with different cutting conditions. They demonstrated that the ceramic tool suffered from flank wear with observed crater wear when machining hardened steel with low-speed conditions and that the adhesion wear between the tool and the machined surface is low. With increasing of cutting speed the adhesion wear are strengthen. However, the proposed tool showed acceptable wear resistance in machining grey cast iron with uniform flank wear.

Liu et al. [56] proposed $\mathrm{Ti}\left(\mathrm{C}_{5} \mathrm{~N}_{5}\right) / \mathrm{TiB}_{2} /\left(\mathrm{W}_{7} \mathrm{Ti}_{3}\right) \mathrm{C}$ as a tool material, and they studied the flexural strength in high temperature, and they demonstrated that deflection point of flexural strength at $800 \mathrm{C}$, and after that degree, the flexural strength decreased quickly.

Mohammedpour et al. [12] thought about enhancing the properties of the cutting tool material by investigating the gradual substation of cobalt with nickel in cemented carbonitrides. Sintered samples were prepared by 


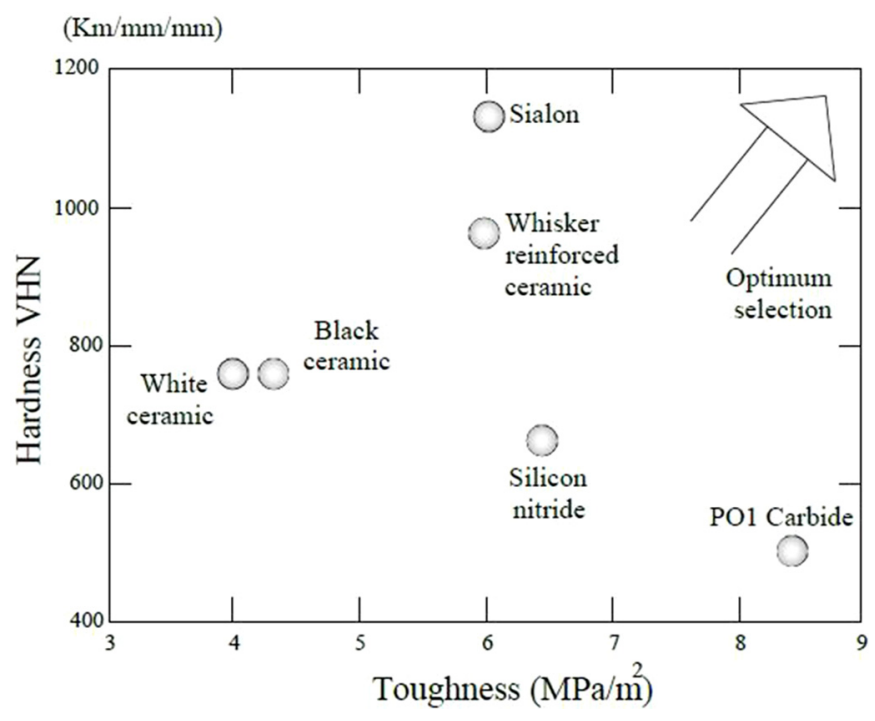

Fig. 4. Comparison of micro-hardness (VHN-1 kg) at $1000^{\circ} \mathrm{C}$ and toughness of ceramic tool materials [23].

metallurgy techniques and the use of isostatic pressures and vacuum furnaces. Complete displacements of cobalt by nickel leads to an increase in transverse rupture strength of the final alloy by $37 \%$ with less than $6 \%$ decrease in Vickers hardness and doubled the thickness of Cubic free layer. While Zhao et al. [57] thought about synthesized in situ growth of tantalum carbide (TaC) whiskers in an $\alpha-\mathrm{Al}_{2} \mathrm{O}_{3}$ matrix powder via a carbo-thermal reduction technique within the temperature range from 1650 to $1500^{\circ} \mathrm{C}$ in an argon atmosphere. $\mathrm{Ta}_{2} \mathrm{O}_{5}, \mathrm{C}, \mathrm{Ni}$, and $\mathrm{NaCl}$ powder are the components of starting material. Most of the prepared whiskers were $0.2-0.5 \mu \mathrm{m}$ in diameter and $5-15 \mu \mathrm{m}$ in length, the reaction temperature $1400-1450{ }^{\circ} \mathrm{C}$ was suitable for growth of $\mathrm{TaC}$ whiskers and a wet mixing method was beneficial to increase the whisker yield, some of the whiskers showed a needle shape, and others showed a screw shape.

\subsection{Mechanical and tribological properties of ceramics}

One of the parameters which has an influence on the selection and manufacturing of cutting tools directly is the hardness; it also effects cutting conditions such as cutting speed, feed, and depth of cut [21]. For example, the $\mathrm{Al}_{2} \mathrm{O}_{3} /$ $\mathrm{SiC}$ particulate composites show high hardness comparing with their unreinforced matrix because of the grain growth restrain by adding $\mathrm{SiC}$ and the presence of a hard secondary phase [58].

Fracture toughness is one of the properties of modern ceramics concerning the brittleness [20]. By adding $\mathrm{SiC}$ whiskers and micro-particles to $\mathrm{Al}_{2} \mathrm{O}_{3}$ matrix, the flexural strength and the fracture toughness of the ceramic material can be enhanced [11]. Figure 4 shows the relationship between the hardness and toughness for different types of ceramic cutting tools [23].

The key to the cutting performance is the tools wear and tool life [28]. The damages are caused by several types of wear such as diffusion between the tool and the workpiece, thermal gradient, abrasion and adhesion [59]. The type of wear depends on the place of worn, for example, abrasive wear is the main wear mechanism in the flank face, and the adhesive wear is the main wear mechanism in the rake face. The depth of cut notch wear is very severe when machining hard-to-cut materials with ceramic tools [43].

Zhou et al. [60] investigated the surface damage which is produced by a whisker ceramic cutting tool in turning Inconel 718, and also the effects of cutting parameters, tool wear, and coolant conditions on the formation of surface defects. It is demonstrated that the types of surface defects, which were found, were in the form of micro sintering and breakage.

Casto et al. [61] studied the commercial ceramic insert cutting tool performance in cutting AISI 310 steel and compared it with the traditional carbide cutting tool. The wear mechanism appeared on the edges of carbide inserts like a notch mechanism especially where the alumina zirconium inserts was predominant, whereas the tools made of SiAlON and alumina with $\mathrm{SiC}$ whiskers showed better performance.

Theoretical models are very effective methods to predict the cutting tool material performance and solving defects of the material Therefore Maohua et al. [62] established a theoretical notch wear model of low-stress value and temperature impact fatigue on the basis of highspeed continuous impact force and tool notch surface temperature acted upon by burr and serrated chip edge. They made the model to solve complex problems and predict the problems which can happen on the ceramic tool. Furthermore, Hvizdos et al. [63] investigated mechanical properties and tribological properties of nano-composites with silicon nitride matrix with addition up to $3 \mathrm{wt}$.\% of different types of graphene platelets. They reported that the addition of the carbon phase with that amount does not affect or decrease the coefficient of friction.

Schulz et al. [64] developed nano $\mathrm{Si}_{3} \mathrm{~N}_{4}$ composites using $\beta-\mathrm{Si}_{3} \mathrm{~N}_{4}$ powders and investigated their wear behavior. The method of decreasing wear in the cutting tool is by creating a cutting tool with self-lubrication. Since the pure $\mathrm{Si}_{3} \mathrm{~N}_{4}$ composites have good wear behavior under dry rolling the TiN reinforced nano $\mathrm{Si}_{3} \mathrm{~N}_{4}$ composites create self-lubrication under dry sliding, so the coefficient of friction and wear rate decreased and fracture toughness was increased.

As mentioned before it is concluded that the cutting tool material must be extremely stable with physical and chemical properties especially at high temperature. Hardness has a direct influence on the selection of the cutting tool material, and it is considered one of the most important factors because of the nature of the machining process which depends on the high hardness of the cutting tool. The continuous friction must also be considered therefore the cutting tools material must have extremely wear resistance, thus high tribological properties must exist in the cutting tool material. The material must also have acceptable mechanical properties such as fracture toughness and flexural strength [65]. 


\subsection{Improvement of cutting properties of ceramic tools by coatings}

A well known type of cutting tool consists of a substrate material with one or more outer layers of coating. The coating is for enhancing wear resistance and cutting tool performance [66]. Coated tools have a composite material structure, consisting of the substrate covered with a hard, anti-friction, chemically inert, and thermally isolating layer. As such, coated tools compared to uncoated ones, offer better protection against mechanical and thermal loads, diminish friction and interactions between tool and chip, and improve wear resistance in a wide cutting temperature range [67]. Hard coatings are thin films and can be of one or more layers with a thickness that can range from a few nanometers to a few millimeters [68,69]. Usually those single or multi layers of coating enhanced the machining process with greater cutting speed, increased the tool life and enhanced the properties of cutting tool material.

In the metalworking industry tools from various types of cutting ceramics, which do not contain defective elements and have a unique combination of high hardness values (HRA 91-94), and heat resistance $\left(1200-1450{ }^{\circ} \mathrm{C}\right)$, are increasingly used. However, cutting ceramics are characterized by low values of viscosity and bending strength, embrittlement and low thermal conductivity with a relatively high coefficient of thermal expansion. Thus a cutting ceramic tool is very sensitive to thermal cycling loads and has a high propensity for micro and macroscopic damage when contact stresses exceed 900 $1000 \mathrm{MPa}$, and this defines a very narrow area of its application (K01-K10 ISO 513: 2004-07). The high probability of unforeseen damage (sudden failure) of the ceramic tool hinders its widespread use in the metalworking industry. Thus, many types of research are aimed to enhance the performance, cutting tool life and mechanical properties of the cutting tool ceramics by adding several layers of coatings to the cutting tool ceramics [70].

Alternatives for integrated management of the characteristics of the cutting process are associated with the dual role of coatings. This is seen in the simultaneous improvement of the surface properties of the ceramic material and the reduction of the thermo-mechanical effect on the contact areas of the cutting tools during the cutting process. It is worth noting that numerous studies have been conducted to improve the cutting properties of ceramic tools by applying functional coatings that are widely used in dry molding technologies. They provide significant economic efficiency while reducing the negative impact on the environment and health [71]. In the process of turning, oxidation, chemical dissolution and frictional wear of cutting tools occur due to high temperature. Therefore, chemical abrasion resistance and a hard coating applied to SiAlON ceramic cutting tools should be an appropriate way to protect the tools and improve their durability characteristics [72].

Bulgan et al. [73] created an $\mathrm{Al}_{2} \mathrm{O}_{3}$ ceramic matrix with 25 vol.\% of submicron particles and nano-sized $\mathrm{SiC}$ particles. They added a coating film to the tool to enhance its reliability. The defect of chipping can be reduced by decreasing the coefficient of friction, frictional forces, and the temperature. They concluded that the proposed tool had enhanced performance.

Chinchanikar et al. [74] created a relationship between the wear and cutting forces during turning within the tool life using two different tool coatings; PVD applied (TiAl)N and CVD applied $\mathrm{TiCN} / \mathrm{Al}_{2} \mathrm{O}_{3} / \mathrm{TiN}$ when turning AISI 4340 steel. Feed and radial components are more influenced by wear and increased when blunting of the cutting edge take place. They also created a model for force wear characteristics.

SiAlON ceramic is a suitable cutting tool material for machining super alloys under dry conditions and high cutting speeds because of its unique mechanical properties [51]. Therefore Liu et al. [72] overviewed SiAlON ceramic and coated SiAlON ceramic cutting inserts with depositing TiCN by physical vapor deposition (PVD). They compared the proposed tool with the same cutting tool but without a coating and they showed that the coated tool was enhanced and had a better performance. Isik [75] did a comparison between TiN (PVD) coated $\mathrm{Al}_{2} \mathrm{O}_{3} / \mathrm{Ti}(\mathrm{CN})$ mixed aluminabased (KY4400) ceramic and CVD coated carbide $\mathrm{TiC} /$ $\mathrm{AI}_{2} \mathrm{O}_{3} /$ TiN (ISO P25) cutting tools when turning austempered ductile irons with hardness 43.5 HRC without cooling fluid. He studied the cutting forces, flank wear, and surface roughness and they were integrated with the tool life. He found that the tool life of the ceramic insert was longer than the coated carbide insert.

Vereschaka et al. [70,76] aimed to increase the efficiency of ceramic cutting tools by using nano-scale multilayer composite coatings applied using innovative arc-PVD processes with vapor ion flow filtration and a diamond-like coating. The three-layer architecture of the nanostructured multilayer composite coatings was also created. The wear mechanism of ceramic tools was studied. This approach allows direct control over the contact characteristics of the cutting process to reduce normal and shear stresses, which increase the likelihood of a tool breaking due to brittle fracture. They succeeded in increasing the tool life and cutting tool performance. Vereschaka et al. [70] investigated the functional role of nano-dispersed multilayer composite coatings deposited on the working surfaces of cutting plates of laminated high-strength ceramics for equipping cutting tools when cutting hardened (highstrength) steels. It is shown that a change in the composition, structure, and properties of coatings allows management of the contact processes during cutting. This increases the contact length, reducing normal contact stresses and the probability of micro and macroscopic destruction of the tool cutting edge. Mathematical cutting models have been developed that establish the dependence of the tool side surface wear, the tangential component of the cutting force, the cutting power and the surface roughness on the cutting conditions of high-strength steels. It has been established that the application of nanodispersed ceramic multilayer coatings on a ceramic tool significantly increases its wear resistance and improves the quality of processing.

Long et al. [77] created a cutting tool by depositing a ( TiAl)N/AlCrO coating on silicon nitride cutting inserts. They studied micro-structure, hardness, micro composition 
(a)

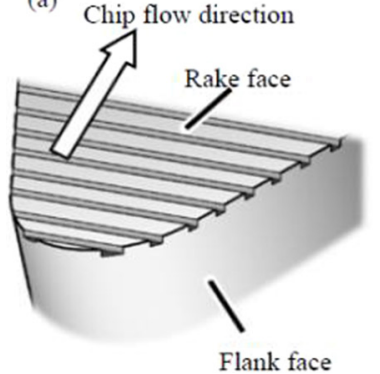

(b)

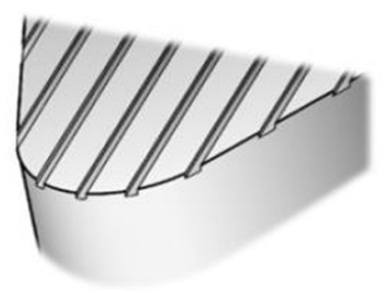

(c)

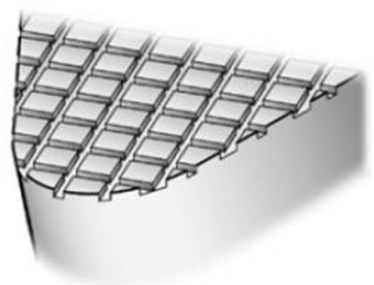

Fig. 5. Examples of textured tools, (a) perpendicular and (b) parallel to the chip flow direction. (c) Cross-patterned texture.

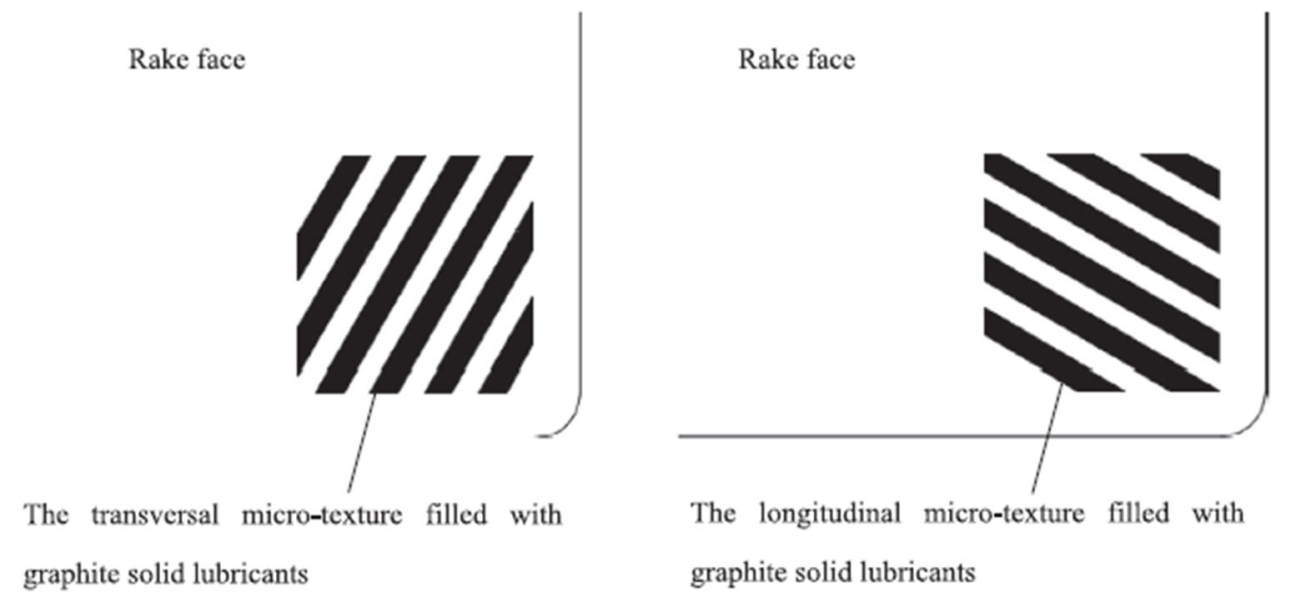

Fig. 6. Pattern of the textured tool [79].

cutting performance and the coating to substrate adhesion when turning HT250 gray cast iron and AISI 4340 steel under a dry environment. They found that high hardness is obtained with ( $\mathrm{TiAl}) \mathrm{N} / \mathrm{AlCrO}$ coating on silicon nitride cutting inserts with acceptable coating to substrate adhesion.

\subsection{Ceramic cutting tool with a textured surface}

The design and geometry of the cutting tool is a significant part of enhancing the performance of the cutting tool. Creating a cutting tool with a textured (or discrete) pattern with different shapes is one of the suitable ways to increase the efficiency of the tool.

Almost every cutting fluid application technique such as flood coolant, cryogenic coolant, and minimum quantity lubrication are costly, toxic, and hazardous. Cutting tool surface texturing focuses more on cutting tool lubrication and investigates the use of internal micro-pool lubrication. It is observed that dimples, micro-holes, channels, grooves, and different textures created on the tool face by surface texturing and filled with lubricant can act as lubricant reservoirs which result in less friction and wear at the chiptool interface [78].

One of the ways to design cutting tools is to create a micro-texture on the surface. It is a micro-cut structure created in the cutting surface. It has a definite shape and size which is located on the cutting edge of the cutting tool [79]. It is observed that the nano-textured tool decreased friction wear with cutting forces comparing with the traditional tool [80]. A surface micro-texture tool is a tiny array structure manufactured, for example, when turning. This has a specific shape and size to be placed in area of the knife-chip contact area of the rake face as shown in Figure 5. A substantial number of studies have shown that different morphologies of microstructure have different effects on the cutting process. Applying the proper morphology of micro-texture can effectively reduce the cutting force, decrease the cutting temperature, and minimize the rake face wear during the dry cutting process; thus, the cutting performance and the tool life can be improved [79]. Cutting performances in dry cutting is also improved by the textured surface [81].

Feng et al. created three ceramic tools with different micro-textured geometry. Figure 6 shows the tool with the texture used in the experiments [79] by using software Advent Edge. The tools are used in the FEM simulation of the cutting process. They showed that the proposed tools could reduce the cutting forces, cutting temperature and enhance the performance of cutting tool when comparing the traditional ceramic tool by simulation and also experimentally by fabrication of the ceramic tool by hotpressed sintering. Graphite grains are formed directly in the microstructure of the ceramic plate. The graphite 

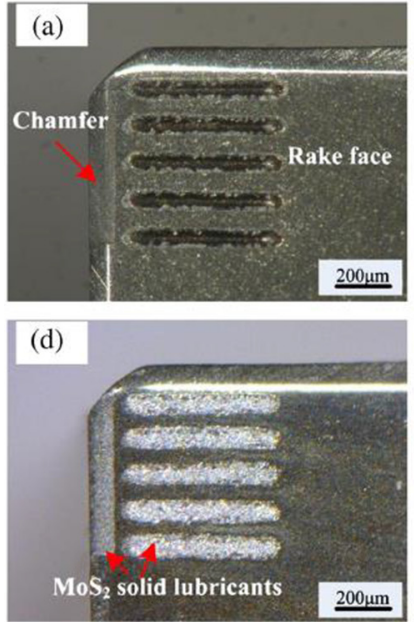
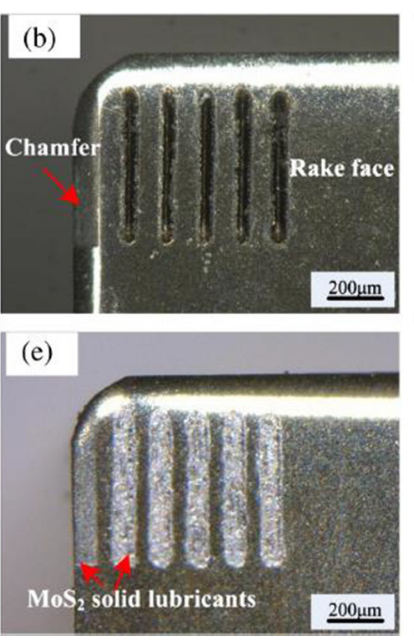
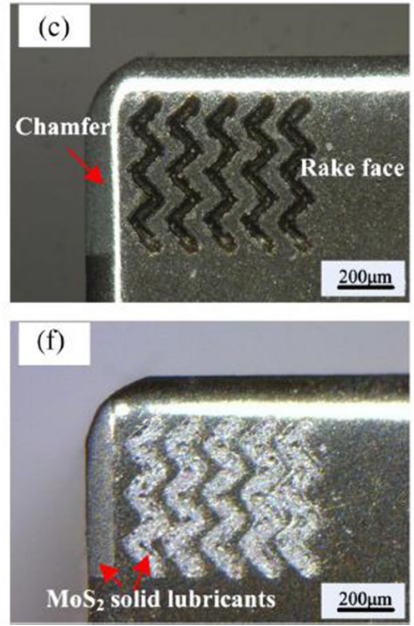

Fig. 7. Different patterns of the textured tool [83].

overflows from the body of the cutter when the tool wears out and covers the rake face and that decrease the friction, cutting forces and temperature.

Moreover Xing et al. [82] produced nano-scale and micro-scale textures with different geometrical characteristics on the surface of $\mathrm{Al}_{2} \mathrm{O}_{3} / \mathrm{TiC}$ ceramic cutting tools material. Molybdenum disulfide $\mathrm{MoS}_{2}$ solid lubricants were embedded or burnished through textures as shown in Figure 7. They studied the effect of texture in the cutting performance in dry machining hardened steel, and also they investigated surface roughness, cutting forces coefficient of friction, tool wear, and chip topography. It is demonstrated that cutting forces, cutting temperature, coefficient of friction and tool wear of the proposed tool were reduced compared with the traditional tool and the micro-scale texture on the rake face is most effective in cutting performance. The proposed tool enhanced the produced surface quality and reduced vibrations.

In this regard, Gajrani et al. [78] proposed a cutting tool with a textured surface over the rake face. It is demonstrated that the proposed tool reduces the cutting forces, the temperature of cutting, the coefficient of friction and tool wear, for a micro and nano-textured cutting tool.

In the same vein, other researchers have carried out similar work but with other tool materials. For example Kawasegi et al. [83] produced a new cutting tool with both micro-scale and nano-scale textures, using the ablation and interface phenomena of a femtosecond laser, and they investigated the tool performance in turning of aluminum alloys. It is demonstrated that the cutting forces were decreased because of the low friction which depends on the direction of texture A lower cutting force resulted from this texture direction which is perpendicular to the chip flow direction rather than the parallel. This was carried out with a high cutting speed over $420 \mathrm{~m} / \mathrm{min}$. Moreover, Rathod et al. [84] proposed two types of textured tool; the first one was linear (perpendicular to the chip flow direction), and the other one was square on plain WC inserts using flowed ion beam machining. They added $\mathrm{MoS}_{2}$ solid lubricants to the proposed cutting tool, and they tested them when machining of Al6063.
They demonstrated that the square textured tool showed better performance in comparison with the linear textured tool in terms of cutting forces and surface finish. In fact the cutting forces of square textured cutting tool were reduced by $30 \%$ however the cutting forces of the tool with linear texture were reduced by $25 \%$. They explained that by reducing the tool-chip contact area, consequently the friction was reduced between the tool and chip.

Another way of designing the tool was with graded nano-composite. Tian et al. [85] fabricated $\mathrm{Si}_{3} \mathrm{~N}_{4} /(\mathrm{WTi}) \mathrm{C}$ graded nano-composite ceramic tool materials with different thickness ratios and number of layers. This was done with hot pressing sintering technology and also they investigated flexural strength, fracture toughness, microstructure ideation cracks, and hardness. It was demonstrated that the optimum results for mechanical properties, flexural strength, and fracture toughness were with five layers graded nano-composites with a thickness of $0.2 \mu \mathrm{m}$.

The residual stresses and mechanical properties can be induced by the graded structure in the surface layer. The stress-strain state of the surface layer in the sintered nonuniform materials may be investigated by the finiteelement method [86]. Figure 8 shows the shape of the proposed ceramic cutting tool.

Self-lubrication tool is one of the significant methods in developing the performance of the cutting tool. Therefore, Wu et al. [87] purposed a new type of the self-lubricating ceramic tool by adding metal coated solid lubricant powders. They produced the coating by electro-plating, techniques. The tool was coated with $\mathrm{CaF}_{2}$ powders and compared with the tool without a coating, the results showed and enhancement in mechanical properties microstructure, better antifriction properties and wear resistance.

The type of machining process, such as intermittent or continuous cutting, affects directly on the tool geometry and its performance thus Cui et al. [88] aimed to optimize the tool geometry parameters for intermittent turning. They determined the initial damage of the ceramic cutting tool based on damage mechanics and obtained the stress 


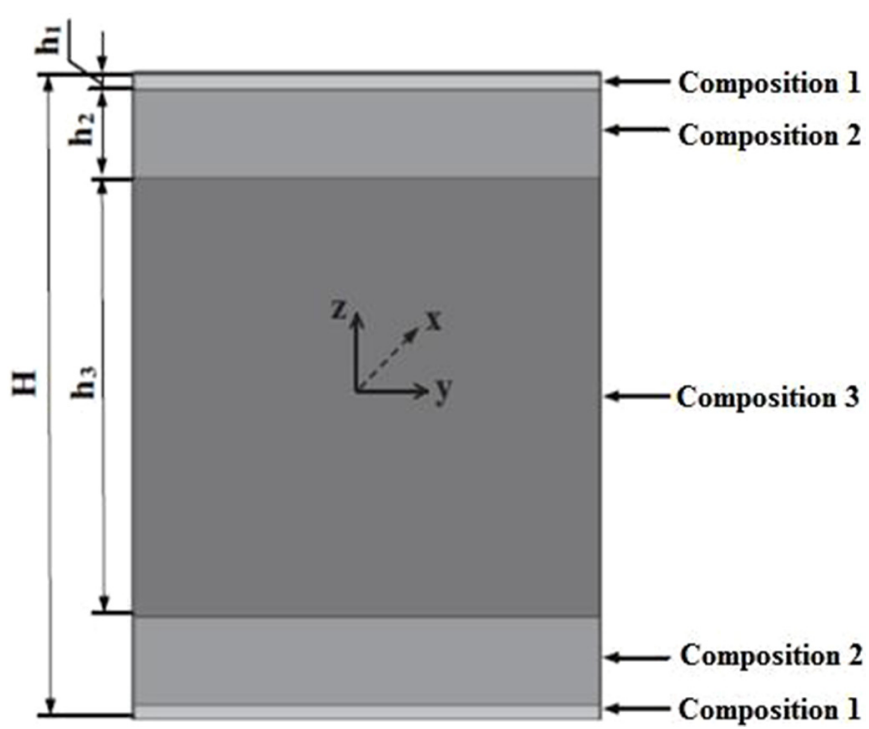

Fig. 8. Cross-sectional graph of the five-layer graded ceramic material with a thickness ratio of 0.2 [85].

distribution on the tool body by the finite element simulation. Different cutting length ratios and the combination of the tool geometry parameters have a relationship to the evolution of maximum damage of equivalent stress. They proposed the highest value of damage equivalent stress in one cutting cycle as a new indicator for optimization of the tool geometry parameters.

Summarizing this section, one of the important ways to enhance cutting tool performance is its design. There are many methods of achieving this such as self-lubrications, or creating the textured pattern with different shapes on the surface of the cutting tool.

\section{The influence of manufacturing methods on the ceramic cutting tool properties}

The fabrication technology of ceramics and composites involves various steps, namely powder synthesis, drying, consolidation, binder-burnout and finally sintering of green compact bodies into useful products. In this process, the sintering step of raw precursor powders is the most important step to produce a product with the desired properties. The main objective of the sintering step is to produce a product with nearly full density, and fine and uniform microstructures leading to optimum properties. Innovations in material processing have always resulted in a better product and often cost-effective processing. There are many heating methods used for synthesis and sintering steps in materials processing. These methods can be broadly divided into two categories: contact and noncontact methods. Most traditional heating methods based on thermal conduction/radiation/convection (such as electric resistance and fuel heating methods) are categorized as contact heating methods in which the thermal energy is in direct contact with the work-piece. Heating methods such as induction, RF (radio frequency) or microwave heating heat the work-piece directly due to

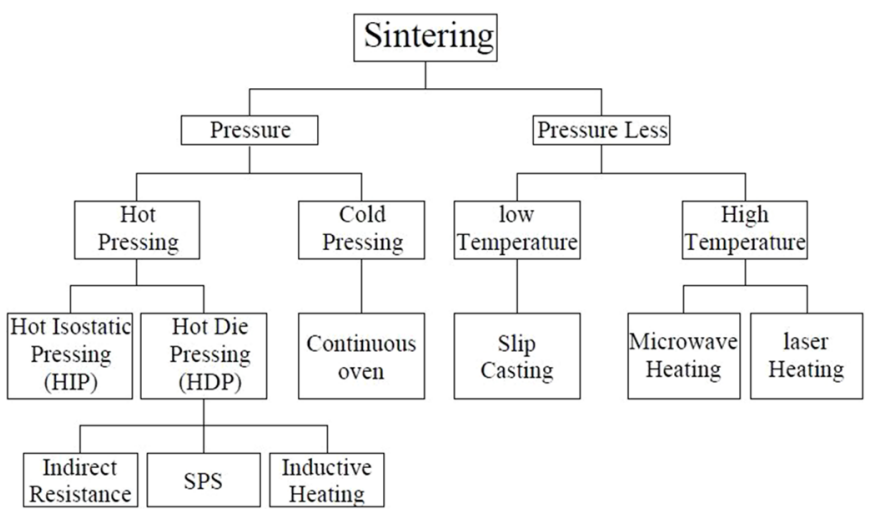

Fig. 9. Classification of the sintering processes.

the coupling of electromagnetic radiation with the matter and are thus called non-contact methods [89].

Sintering contains several processes, and they work starting from setting powders and adding additives then compacting and forming the powder material such as ceramics and metals into the solid-state. This is followed by the furnace and exposure to heat and pressure. It should be noted that the temperature is under the melting point. The sintered particles are bonded together by atomic transport mechanisms and the particle growth results in a decrease in porosity [90]. Sintering process aims to produce densitycontrolled materials and components from ceramic and metal powders by existing thermal energy. Hot pressing is a general method to produce the ceramic cutting tool. Figure 9 shows the different types of sintering processes.

Spark plasma sintering (SPS) is one of types sintering which depends on forces with uni-axial direction combined with pulsed (on-off) direct electrical current in the case of low atmospheric pressure which causes acceleration of consolidation of the powder. There are several names for that process such as pressure-assisted pulse energizing process or the pulsed electric current sintering process.

The SPS techniques enable the sintering of bonding particles at a short holding time and low temperature with electrical energy and high-temperature spark plasma. The SPS process aims to decrease the grain growth through the grain boundary and the stresses opposing grain growth generating from the thermal mismatch between the matrix and the dispersed particles [91].

Conventional sintering requires very high temperatures and a long holding time, which leads to a deficient mechanical performance [92]. Control of sintering temperature is possible through setting the holding time, ramp rate, pulse duration, and pulse current and voltage. The direct current pulse discharge could generate spark plasma, spark impact pressure, Joule heating, and an electrical field diffusion effect $[93,94]$.

The sintering atmosphere directly affects the properties of the material being sintered. Thus the densification kinetics, phase stability, stoichiometry, and grain growth are affected by the sintering atmosphere [91]. Certain gaseous species with low solubility and diffusivity in certain powders can be entrapped in closed pores and oppose the sintering mechanisms due to pressure build-up [95]. 
High velocity sintering processes can minimize grain growth and manufacture a harder sintered compact with a high relative density of $99-100 \%$ and a hardness of over $20 \mathrm{GPa}$. Pressurized sintering allows for the direct sintering from powders to near-net shape dimensions of a ring or cylindrical shape, and eliminating the green body compaction process of usual pressure-less sintering. The sintering conditions were an SPS temperature of $1673-1873 \mathrm{~K}$ with heating-up and holding time approximately $15-20 \mathrm{~min}$ totally and applied pressure of $30-50 \mathrm{MPa}$. The tolerances of as-sintered parts are within $0.2-0.3 \mathrm{~mm}$ so that it is easy to obtain a final finishing accuracy by conventional mechanical grinding at post-processing [96].

Alumina oxide is one of the most widely used ceramic materials owing to its attractive properties, low cost, and less demanding sintering conditions. However, like other ceramic materials, it suffers brittle fracture under loadbearing conditions, which limits its application as a loadbearing material. Over the years many studies have been dedicated to improving the toughness and strength of alumina ceramics through methods such as:

- Dispersing a small amount of a harder phase such as $\mathrm{SiC}$, $\mathrm{Si}_{3} \mathrm{~N}_{4}$, and $\mathrm{ZrO}_{2}$.

- Dispersing with a ductile phase such as metallic particles $(\mathrm{Cr}, \mathrm{Ni}, \mathrm{Cu})$ or high-strength phases such as carbon nanotubes (CNTs) or graphene nano-platelets (GNPs) [90].

The heating rate during the SPS process depends on the geometry of the container/sample ensemble, its thermal and electrical properties, and on the electric power supplier. Heating rates as high as $1000^{\circ} \mathrm{C} / \mathrm{min}$ can be achieved. As a consequence, the processing time typically takes some minutes depending on the material, dimensions of the piece, configuration, and equipment capacity [97]. However, the use of conventional sintering methods such as hot pressing, high-temperature extrusion, and hot isostatic pressing to consolidate these materials often results in grain growth which affects the properties of the end product. Preventing or at least minimizing grain growth to maintain the nanostructure features of the matrix is possible through careful control of consolidation parameters, particularly heating rate, sintering temperature, and time. In this regard, spark plasma sintering (SPS), also known as field assisted sintering (FAST), is an effective nonconventional sintering method for obtaining fully dense materials [94]. The main aim is a minimization of grain growth through grain boundary pinning and the introduction of stresses opposing grain growth emanating from the thermal mismatch between the matrix and the dispersed secondary particles [91].

Microwave sintering is considered a relatively new ceramic material processing technique that differs significantly from conventional sintering methods due to the nature of the heat transfer mechanisms involved. Hence, microwave sintering is classified as a non-conventional sintering technique. This method presents itself as a fast, economical, and flexible processing tool. Some of the most important advantages against conventional sintering systems include lower energy consumption and production costs, reduction of processing times, higher heating rates, and, in some cases, even an improvement in the physical properties of the consolidated material. As a consequence, scientific interest in this novel technique is increasing [98].

\subsection{Contact manufacturing methods}

\subsubsection{Hot pressing}

One of the most important tasks for an advanced processing technology is to obtain a significant increase in the durability of the cutting tools, through the use of powder metallurgy in order to increase the cutting speed. There is a need for more stringent requirements for the sintered tool materials, especially their mechanical properties and wear resistance [99].

Gevokyan et al. [100] studied hot pressure sintering under alternating current. They used aluminum oxide and tungsten mono-carbide powder of submicron grain size to manufacture a sintered structure under different conditions such as temperatures and pressures. The cutting tool inserts are made from the nano-sized mixture of the $\mathrm{Al}_{2} \mathrm{O}_{3}$ and $\mathrm{WC}$ powders by a ratio of $50-55 \%$. Comparing the proposed cutting tool with commercial one showed that the plates have an increased durability (up to $30 \%$ ) and the sintered material grains became smaller than $1 \mu \mathrm{m}$ and had better properties.

Another work by Li et al. [101] proposed a new ceramic tool material $\left(\mathrm{Al}_{2} \mathrm{O}_{3} / \mathrm{TiB}_{2} / \mathrm{TiSi}_{2}\right)$ by manufacturing it by a vacuum hot pressing technique. $\mathrm{TiSi}_{2}$ was added into the composite because of its oxidation susceptibility to crack healing of ceramics. They studied the effects of $\mathrm{TiSi}_{2}$ content, sintering temperature and sintering duration time on mechanical properties and microstructure of the material. The dosage of $\mathrm{TiSi}_{2}$ increased so that the average grain size decreased, but the high percentage of $\mathrm{TiSi}_{2}$ may cause abnormal growth of grain. It was found that there was transgranular fracture and intergranular fracture on the fracture surface. It was demonstrated that the optimized $\mathrm{TiSi}_{2}$ amount was $15 \mathrm{wt} \%$, the optimized sintering parameters of the ceramic tool material were; sintering temperature $1600{ }^{\circ} \mathrm{C}$, pressure $32 \mathrm{MPa}$, duration time $30 \mathrm{~min}$.

With the same idea but another composition, Wang et al. [102] produced $\mathrm{TiN} / \mathrm{TiB}_{2}$ composite ceramic cutting tool material by hot-pressed sintering in a vacuum and investigated the effects of sintering temperature and $\mathrm{Ni}$ additive on the mechanical properties and microstructure. They demonstrated that with increasing sintering temperature the fracture toughness decreased, but firstly the flexural strength of $\mathrm{TiN} / \mathrm{TiB}_{2}$ composite increases then decreases with increasing sintering temperature and the same condition with additive $\mathrm{Ni}$ for $\mathrm{TiN} / \mathrm{TiB}_{2}$, but the fracture toughness increases consistently with an adding of $\mathrm{Ni}$ additive.

Zin et al. [103] prepared $\mathrm{TiB}_{2} / \mathrm{TiC}$ composite powder by ball milling in ethanol then vacuum drying. The $\mathrm{TiB}_{2} /$ $\mathrm{TiC} / 8$ wt.\% nano-Ni composite ceramic cutting tool material was sintered using a vacuum hot pressed sintering technique by six processes which including different holding stages and times. They investigated the effect of sintering processes on the mechanical properties and microstructure. They demonstrated that the mechanical 
properties and microstructure depended on the holding time. The long duration of the process led to changes in the grain size of $\mathrm{TiB}_{2}$ and $\mathrm{TiC}$, the formation of pores and brittle damage to the plates, resulting in the mechanical properties of the composition $\mathrm{TiB} 2 / \mathrm{TiC} / 8 \mathrm{wt} . \%$ nano $\mathrm{Ni}$ becoming deteriorated. However, the use of the SPS process showed a significant improvement in mechanical properties due to the formation of a thinner microstructure and higher relative density, thus its flexural strength, fracture toughness and hardness improved.

Yin et al. [24] reinforced an $\mathrm{Al}_{2} \mathrm{O}_{3}$ based composite ceramic tool material with micro-scale and nano-scale $\mathrm{TiC}$ particles with different contents of cobalt. Additionally, they investigated the mechanical properties and microstructure. The optimal mechanical properties are in $\mathrm{Al}_{2} \mathrm{O}_{3} /$ TiC micro-nano-composite containing 3 vol.\% Co which was sintered under pressure of $32 \mathrm{MPa}$ at $650{ }^{\circ} \mathrm{C}$ in vacuum for $20 \mathrm{~min}$. They found that the mechanical properties increased and then decreased as the cobalt increased, however low content of cobalt lead to poor relative density and leads to cobalt cause micro cracks at grain boundaries, the existence of interface cobalt could decrease the stress concentration and value of tensile stress in $\mathrm{Al}_{2} \mathrm{O}_{3}$ matrix. Micro-scale and nano-scale $\mathrm{TiC}$ particles improve the flexural strength and fracture toughness. Micro-scale $\mathrm{TiC}$ deflects and bridges the cracks. Whereas, Fazhan et al. [104] proposed WC matrix composite tool material and produced it by the hot pressing technique in machining titanium alloy $\mathrm{Ti}_{6} \mathrm{Al}_{4} \mathrm{~V}$, and they studied the cutting performance and wear mechanisms of the tool.

Taguchi et al. [105] discussed the oxidation behavior of $\mathrm{Si}_{3} \mathrm{~N}_{4} / \mathrm{Y}_{2} \mathrm{Si}_{2} \mathrm{O}_{7}$ ceramics at $100^{\circ} \mathrm{C}$ and $1200^{\circ} \mathrm{C}$. They sintered $\mathrm{Si}_{3} \mathrm{~N}_{4}$ samples from liquid phase using 7 and 14 vol. $\%$ of $\mathrm{Y}_{2} \mathrm{Si}_{2} \mathrm{O}_{7}$ as a sintering additive. The density of the sintered samples reached $99 \%$. The samples heated under stationary air for different periods between 0 and $256 \mathrm{~h}$. They demonstrated that $\mathrm{Si}_{3} \mathrm{~N}_{4}$ has high oxidation resistance at 1000 and $1200{ }^{\circ} \mathrm{C}$ in the air when the volume of additives is high.

Rutkowski et al. [106] studied silicon nitride based composites with up to 10 wt.\% nano-flakes (GPN) addition. They measured the mechanical properties and elastic properties like fracture toughness, bending strength and Knoop hardness. It is shown that such a tool can be used with a cutting speed of $75 \mathrm{~m} / \mathrm{min}$ only in machining NC6 steel. However in machining grey cast iron cutting speed can be $800 \mathrm{~m} / \mathrm{min}$, but it could decrease the tool life, and it would be less than the traditional pure silicon nitride material.

Yin et al. [107] also worked on alumina-based material. They fabricated ceramic tools by hot pressing technology with alumina-based composite ceramic tool material reinforced with carbide particles. Metallic phase added into the composite ceramic is a choice based on the distribution of the residual stresses. They investigated the effects of metallic phase on mechanical properties and microstructure. By refining microstructure, filling pores and enhancing interfacial bonding strength could support room temperature mechanical properties. However it also effects shaping strength degradation at high temperature because of the oxidation of the metallic phase and gets soft at high temperature in the air. They demonstrated that the fracture toughness of composite was enhanced with a metallic phase because of the lower residual stress in the matrix and interaction of a more effective energy consuming mechanism, such as cracks bridged by particle crack deflection and intergranular grain. Zhao et al. [11] studied the effects of adding TiC nano-particle content size of particles and setting processes on the mechanical properties of hot-pressed $\mathrm{Al}_{2} \mathrm{O}_{3} / \mathrm{SiC}_{\mathrm{w}}$ ceramic tool. They demonstrated that the hardness and fracture toughness is increased with increasing $\mathrm{TiC}$ percentage. $\mathrm{TiC}$ percentage is $4 \mathrm{vol} . \%$ and particle size of $40 \mathrm{~nm}$ is the best flexural strength. They were concerned with the influence of particle size on flexural strength, hardness, and fracture toughness. They noticed that decreasing $\mathrm{TiC}$ particle size increased flexural strength because of the enhanced density and refined grain size of the composite. This was due to the dispersion of smaller TiC particles sizes. The whiskers were distributed along a direction perpendicular to the hot pressing direction. Fracture toughness is enhanced by whisker crack bridging, crack deflection and whisker pullout.

Kun et al. [108] compared and studied the mechanical properties and microstructure of a proposed sintered tool made of silicon nitride based nano-composites which are prepared with different amounts (1 and 3 wt.\%) of multilayer graphene (MLG) as well as exfoliated graphite nano-platelets $(\mathrm{xGnP})$ and nano graphene platelets. They found that graphene platelets were included with porosity in the matrix. The bending strength and elastic modulus of $\mathrm{MLG} / \mathrm{Si}_{3} \mathrm{~N}_{4}$ composites were enhanced when compared to other graphene added silicon nitride ceramic composites.

Theoretical methods are useful to predict the performance and the ability of the cutting tool. Zhao et al. [109] designed a model for a functionally gradient ceramic tool material with symmetrical composition distribution. The $\mathrm{Al}_{2} \mathrm{O}_{3} / \mathrm{TiC}$ functionally gradient ceramic tool material was fabricated by powder laminating and uni-axially hotpressing techniques. The thermal shock resistance of $\mathrm{Al}_{2} \mathrm{O}_{3}$ was evaluated by water quenching and three-point bending tests of flexural strength. The functionally gradient ceramics exhibited higher retained tension under all thermal shock temperature differences compared to homogenous ceramics, indicating their higher thermal shock. They supported their results by calculations of the transient thermal stress field. They also investigated the performance of the cutting tool in the rough turning of the cylindrical surface of an exhaust valve of a diesel engine in comparison with commercial $\mathrm{Al}_{2} \mathrm{O}_{3} / \mathrm{TiC}$ ceramic tool material. They demonstrated that the tool life is longer than the common one by $50 \%$ because the latter is affected by thermal shock cracking accompanied with mechanical shock, however the proposed tool is affected by fatigue crack extension rather than the thermal shock.

Pfeifer et al. [110] studied the effect on the microstructure of silicon nitride based nano-composites with different carbon additions. The nano-composite containing $\mathrm{Si}_{3} \mathrm{~N}_{4}$ and $\mathrm{C}$ on the proportion of $1-10 \mathrm{wt} . \%$ carbon $(\mathrm{CNT})$ or carbon black (CB) and graphite or graphene. They produced specimens by hot isostatic pressing. They obtained the tribological characteristics for $\mathrm{Si}_{3} \mathrm{~N}_{4}$. However 
Tian et al. [111] created another type of silicon nitride, they proposed $\mathrm{Si}_{3} \mathrm{~N}_{4} /(\mathrm{WTi}) \mathrm{C} / \mathrm{Co}$ nano-composite ceramic tool materials with a multi-layered structure by hot pressing technique. The composite without Co was used as the surface layers, and the composites containing Co were the inner layers. They studied the flexural strength, fracture toughness and the hardness of the composite and observed fracture surface and dentations cracks. It showed that the flexural strength and fracture toughness were increased by the graded structure and high hardness still maintained. They designed five layers graded nano-composites with a thickness ratio of 0.2 sintered pressures $30 \mathrm{MPa}$ at $1700^{\circ} \mathrm{C}$ vacuum conditions for $45 \mathrm{~min}$. They found optimum mechanical properties with flexural strength $992 \mathrm{MPa}$ hardness $17.83 \mathrm{GPa}$ fracture toughness $10.5 \mathrm{MPa} / \mathrm{M}^{1 / 2}$.

Song et al. [112] fabricated $\mathrm{TiB}_{2} / \mathrm{WC} / \mathrm{TiC}$ ceramic tool material composites by hot pressing sintering at a temperature at approximately $1650{ }^{\circ} \mathrm{C}$, they added $\mathrm{WC}$, $\mathrm{TiC}, \mathrm{Mo}$ and Co to make a liquid phase and enhance the densification. The effects of addition $\mathrm{TiC}, \mathrm{Co},(\mathrm{Mo}, \mathrm{Ni})$ were investigated. It demonstrated that $\mathrm{TiC}$ reduces the defects such as pores and microstructure, and the results showed that the microstructure of $(\mathrm{Mo}, \mathrm{Ni})$ and Co which added to $\mathrm{TiB}_{2}$ were identical, the core was $\mathrm{TiB}_{2}$ and $\mathrm{TiC}$ was at the rim. As the $\mathrm{TiC}$ increased the flexural strength, density and microhardness were increased. It demonstrated that $\mathrm{TIB}_{2} / \mathrm{WC} 30 \mathrm{wt} . \%$ was the best combination for a dense microstructure and mechanical properties.

Zhao et al. [113] produced new $\mathrm{TiB}_{2}$ composite ceramic tool materials by hot pressing and they added a different percentage of $\mathrm{TiC}$ and $\mathrm{SiC}$. In ambient air with various temperatures from 800 to $1300^{\circ} \mathrm{C}$; mechanical properties, flexural strength, composition, and microstructure were investigated. They found that TTS3 $\left(\mathrm{TiB}_{2}-8.1 \mathrm{wt} . \% \mathrm{TiC}-\right.$ 16.4 wt. $\% \mathrm{SiC}$ ) when compared with TTS $\left(\mathrm{TiB}_{2}-15.9\right.$ wt. $\%$ $\mathrm{TiC}-10.6$ wt.\% $\mathrm{SiC})$ and $\mathrm{TS}\left(\mathrm{TiB}_{2}-22.4\right.$ wt.\% $\left.\mathrm{SiC}\right)$ had optimum results for all the properties.

\subsubsection{Spark plasma sintering}

Spark plasma sintering (SPS) is an advanced technology with a high potential for material processing. SPS is very similar to hot pressing (HP) but differs from the latter by the source of heat. For SPS, a pulsed DC is supplied through the matrix and thus acts as a heat source due to the Joule effect. It should be noted that the goal of most SPS studies is to minimize grain growth to obtain dense nanostructured materials.

The system consists of an SPS sintering press machine with a vertical single-axis pressurization mechanism, specially designed punch electrodes incorporating a water cooler, a water-cooled vacuum chamber, a vacuum/air/ argon-gas atmosphere control mechanism, a DC pulse sintering power generator, a cooling-water control unit, Z-axis position control unit, and a temperature measuring unit [96]. Figure 10 illustrates the mechanism of SPS schematically [93].

When sintering the compacted powder is clamped between the die and the punch to which the electrodes are connected. After that, a spark discharge lights up, thanks to which it becomes possible to obtain a high contact

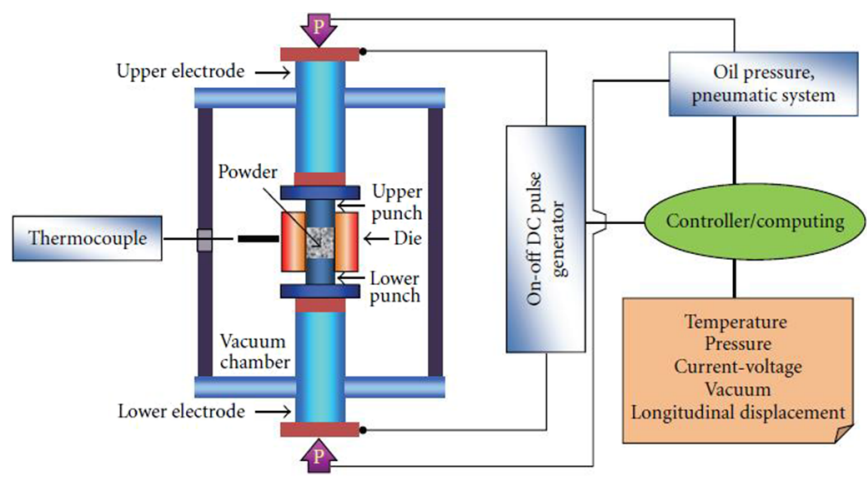

Fig. 10. SPS system configuration [93].

temperature, leading to thermal and electrolytic diffusion between the particles. The SPS process takes place at a temperature between 1000 and $2500^{\circ} \mathrm{C}$ [97]. The distribution of heat and the temperature difference between the core and the edges of the workpiece will be determined by its thermal conductivity, the time of the process cycle and the power input [114]. Much attention should be paid to the growth of grain in the sintered ceramics, as this will significantly affect its mechanical and sometimes optical properties [115].

Conventional electrical hot press processes use DC or commercial AC power, and the main factors promoting sintering in these processes are the Joule heat generated by the power supply or high-frequency induction heating elements and the plastic flow of materials caused by the hydraulic or mechanical driving pressure [96]. When sparking occurs, a high-temperature field with sputtering phenomena generated by the spark plasma and spark impact pressure eliminates adsorptive gases and oxide films and impurities existing on the surface of the powder particles. The action of the electromagnetic field enhances high-speed diffusion due to the fast migration of ions. The application of the pulse voltage induces various phenomena [95]. The local high-temperature state is observed as a bridging, evaporation, solidification and re-crystallization phenomena.

High-pressure spark plasma sintering (HP SPS) is another option of the well-proven spark sintering method for sintering materials, especially superhard polycrystalline diamond or cubic boron nitride, ceramic composites, nanopowders, or refractory substances. Using this and other SPS methods, ceramics can also be synthesized with metastable phases or intermetallic alloys [116].

High-pressure spark plasma sintering (HP SPS) techniques were tested and applied to a Ti-10Al-20Si inter-metallic alloy using a pressure of $6 \mathrm{GPa}$ and temperatures ranging from $1045^{\circ} \mathrm{C}$ to $1324^{\circ} \mathrm{C}$. The low-porosity consolidated samples consist of $\mathrm{Ti}_{5} \mathrm{Si}_{3}$ silicides in an aluminide base. The hardness changed between 720 and $892 \mathrm{HV}$ [117].

The sintering process is accompanied by uniaxial compression. The magnitude of the applied force will be limited by the high-temperature fracture strength of the graphite press tool $(100-150 \mathrm{MPa})$. The increased pressure will somewhat restrain the growth of grain. The short 


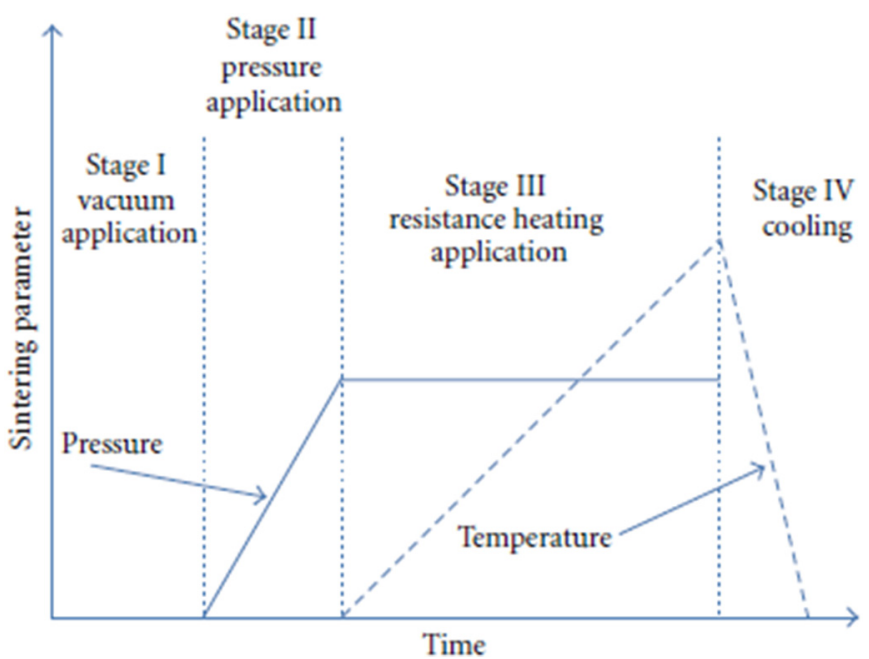

Fig. 11. Spark plasma sintering stages [93].

sintering time and the fast heating rate prevent the interaction between the workpiece and the graphite tool, thereby reducing contamination [118]. Of course, there is a dependence on the physical properties of the sintered material and the size of its particles [119].

SPS is carried out in four main stages (Fig. 11). First, there is a vacuum treatment installation for sintering. Then the sample warms up. After that, the pressing mode is activated. In this case, at the point of contact of the powder particles, a spark discharge occurs and a zone of local overheating with a temperature of several thousand degrees appears. The surface of the grains of the powder melt, the necks appears between them [120]. The last stage is cooling.

Differences in electrical effects are influenced by the conductivity of the compressed material. In the case of current-conducting powders, the heating is due to Joule heating. Of course, there may be some heterogeneity caused by the porosity of the workpiece [91].

Ramirez et al. [121] created two $\mathrm{Si}_{3} \mathrm{~N}_{4}$ containing graphene nanostructures with different graphene sources, pristine graphene nano-platelets, and graphene oxide layers produced by SPS. With composite $60 \beta / 40 \alpha-\mathrm{Si}_{3} \mathrm{~N}_{4}$ and $\sim 300 \mathrm{~nm}$ grain size with a 4 vol.\% reduced graphene oxide shows a toughening increase of $135 \%$ and $10 \%$ in flexural strength. Thicker graphene nano-platelets showed an increased $40 \%$ in toughness and about $10 \%$ increase in flexural strength. The differences depended on the variations in the graphene $/ \mathrm{Si}_{3} \mathrm{~N}_{4}$ interface characteristics and extent monolayer graphene exfoliation.

Mozaheri et al. [122], considered producing Multi-walled carbon Nano-tubes (MWCNT)/nanostructure Zirconium composites with a homogenous distribution of different MWCNT quantities (ranging within 0.5-5 wt.\%). By using spark plasma sintering, they succeeded in keeping the MWCNTs attached to zirconium grains and in obtaining fully dense materials. This reduced the grain growth and kept the nano-size structure. In this regard, Liu et al. [123] also overviewed a study to determine the efficiencies of new material of graphene platelet/zirconium-aluminum composite (GPL/ZTA). Objects are produced by SPS at different temperatures. They obtained GPL $/ \mathrm{ZrO}_{2} / \mathrm{Al}_{2} \mathrm{O}_{3}$ powdered by ball milling of graphene platelets and alumina powders using ultra stabilized $\mathrm{ZrO}_{2}$ balls. They showed that the GPLs were uniformly distributed in the ceramic matrix at $1550^{\circ} \mathrm{C}$; GPL/ZTA and the composites had full density, maximum hardness, and fracture toughness. ZTA composites showed an increase in resistance of about $40 \%$ due to the addition of graphene platelets.

Meanwhile, Gutierrez-Gonzalez et al. [8] prepared $150 \mathrm{~mm}$ diameter samples of $\mathrm{Al}_{2} \mathrm{O}_{3} / \mathrm{SiC}_{\mathrm{w}}$ and $\mathrm{Al}_{2} \mathrm{O}_{3} /$ $\mathrm{SiC}_{\mathrm{w}} / \mathrm{TiC}$ composite disks produced by spark plasma sintering. The physical and mechanical properties were investigated in different areas of the disks to obtain the efficiency of homogeneity of the sintering process. They demonstrated that the incorporation of $\mathrm{TiC}$ as a reinforcing phase to the $\mathrm{Al}_{2} \mathrm{O}_{3} / \mathrm{SiC}_{\mathrm{w}}$ composite enhanced the mechanical strength, hardness, and densification.

In the SPS process, the sintering temperature is usually measured inside the wall of a graphite matrix with a thermocouple or surface using a pyrometer, and not directly in the powder. Thus, there are differences in temperature between the measured value and the actual temperature of the filled powder [96]. It was found that the sintering temperatures in both metals and ceramics by SPS were about $50-250^{\circ} \mathrm{C}$ lower than in the middle of filled powder material [124].

Heating occurs using a sufficiently low voltage (about $10 \mathrm{~V}$ ) by a current up to $10 \mathrm{kA}$. The temperature that can be obtained using graphite tooling reaches $2400^{\circ} \mathrm{C}$. The chamber is cooled at a speed of $150^{\circ} \mathrm{C} / \mathrm{min}$. It can be increased to $400{ }^{\circ} \mathrm{C} / \mathrm{min}$ using additional gas cooling [119].

\subsubsection{Comparison between the spark plasma sintering and high-pressure sintering ceramics}

The features of the ceramic material sintering processes will be determined primarily by the equipment and tooling used. The technology of hot pressing involves heating in the furnace of the preform at a temperature slightly lower than the melting temperature from a few minutes to several hours. In the SPS synthesis, the sample is heated from the inside by passing current pulses through it. In this case, there is no need for preforming. The sintering occurs inside the graphite matrix. The SPS is characterized by the lower sintering temperature, the shorter holding time, the smaller grain growth, the suppressed powder decomposition and the strong preferential orientation effect in the resulting workpiece [116]. Also, among the advantages of SPS method over hot pressing systems should be noted the ease of installation management, the ability to adjust the power, the relative speed of the process, its satisfactory reproducibility and reliability. The SPS compared to conventional hot pressing is shown in Figure 12.

In the case of hot pressing when the blank from the powder is heated by external heating elements due to radiation and convection of inert gas, it becomes difficult to obtain a high heating rate and the process can be very long. This results in overconsumption of electricity, the cost of which for the case of SPS is three to five times less [96]. The sintering temperature for SPS technology, although it 

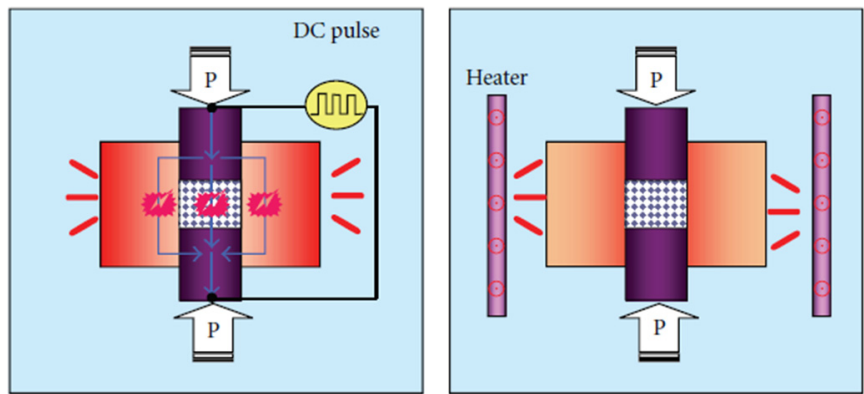

Fig. 12. Comparison between SPS and conventional sintering [94].

Table 2. Characteristics of SPS and HP sintering [96].

$\begin{array}{ll}\text { SPS } & \text { HP } \\ \text { Sintering } & \text { Sintering }\end{array}$

\begin{tabular}{lll}
\hline Temperature gradient sintering & + & $\times$ \\
Grain boundary controlled & + & $\times$ \\
sintering & & \\
$\begin{array}{l}\text { Fine crystalline structure } \\
\text { controlled sintering }\end{array}$ & + & $\times$ \\
$\begin{array}{l}\text { Temperature rise rate } \\
\text { Sintering time }\end{array} \quad+$ & $\times$ \\
$\quad$ Temperature rise time & Fast & Slow \\
$\quad$ Holding time & Short & Long \\
Homogenous sintering & - & - \\
Productivity & + & $\Delta$ \\
Investment in equipment & - & $\Delta$ \\
Running cost & + & $\Delta$ \\
\hline
\end{tabular}

Excellent (+), Good (-), Fair ( $\Delta)$, Difficult $(\times)$.

reaches $2000 \mathrm{C}$, usually remains $200-500^{\circ} \mathrm{C}$ lower than for the case of hot pressing. Also the duration of the process is much shorter being approximately 20 min, including the time to warm up the object and its exposure. In the SPS process, the surface of the powder particles is more easily cleaned and activated, which improves the quality of the resulting ceramics. Some characteristics of SPS and hot pressing technologies are shown in Table 2.

Figure 13 clearly shows there is a much smaller temperature difference, $\Delta T$, between the edge $\left(T_{\mathrm{A}}\right)$ and center $\left(T_{\mathrm{I}}\right)$ of the SPS sample as opposed to the hot-pressed object. A common phenomenon for a hot pressing method is a large temperature difference between the outside and the core of the compact, which often leads to the development of cracks in the sintered samples. In the case of SPS, the temperature gradient is much weaker, which significantly reduces residual stresses [91].

However, it should be noted that SPS technology has its problems. Although there is an adequate electrical conductivity in the powders to achieve the uniform temperature distribution in the sample significant electromagnetic interference affects the intensity and shape of
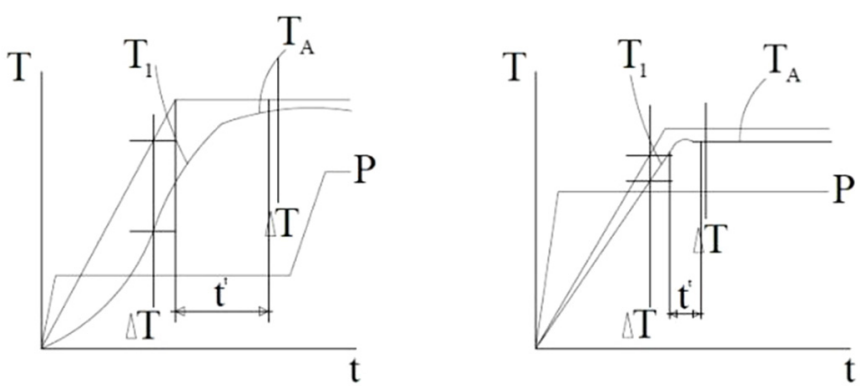

Fig. 13. Comparison of the temperature profile in hot pressing left and SPS right [91].

the electric current pulse. Of course, there are some technological methods that minimize such a negative impact [97].

\subsection{Non-contact manufacturing methods}

\subsubsection{Microwave sintering}

Microwaves have been used since the 1960 for heating purposes, particularly for food- and water-based products. Industrially, the use of microwave energy has become increasingly important because it represents an alternative to traditional methods with high-temperature processes. For example it has been employed in wood drying, resin curing, and polymer synthesis. The growing interest in industrial microwave heating is due mostly to the reduction of production costs resulting from lower energy consumption and shorter processing times. However, several aspects need to be still investigated as each material behaves differently in the presence of microwaves. The application of microwave heating has now expanded to material science and technology, beginning with process control and moving onto ceramic drying, powder calcinations, and decomposition of gases with microwave plasma, in addition to powder synthesis [98].

Traditional processing techniques include hot isostatic pressing, mold casting, and sintering in conventional ovens. As ceramics require very high processing temperatures compared to metals and polymers, these processes tend to be very energy intensive and result in higher production costs to the manufacturers. Therefore, new technologies known as nonconventional sintering techniques, such as microwave technology, are being developed in order to reduce energy consumption, while maintaining or even improving the characteristics of the resulting ceramic material. This novel and innovative technology aims at helping industrial sectors lower their production costs and, at the same time, lessen their environmental impact [98].

The use of microwaves in ceramic processing is a relatively recent development. They can be applied effectively and efficiently to heat and sinter ceramic objects [125].

Many traditional and advanced ceramics have been processed by microwave with reported enhancements in reaction, and diffusion kinetics exhibiting better properties than the conventionally processed material [89]. 
Particularly, microwave sintering represents an interesting opportunity for consolidating advanced ceramic materials with reduced processing time and energy consumption by utilizing electromagnetic radiation to provide high-enough temperatures that allow full densification of the material. The most important advantages of microwave sintering against conventional sintering methods are listed as follows [98]:

- Shorter sintering time and lower energy consumption.

- Higher heating rates can be used.

- Materials with a finer (nano-metric) microstructure with a high degree of densification and enhanced mechanical properties may be obtained due to the densification mechanisms involved.

- Flexible due to the possibility of processing near-netshape materials.

Microwaves are a small part of the electromagnetic spectrum with wavelengths ranging from $1 \mathrm{~mm}$ to $1 \mathrm{~m}$ in free space and frequency between $300 \mathrm{GHz}$ and $300 \mathrm{MHz}$, respectively. However, for research and industrial applications only very few energy bands are allowed. The most common worldwide microwave frequency is $2.45 \mathrm{GHz}$, used for almost all research in materials processing. Based on the microwave matter interaction, most materials can be divided into three categories: opaque (bulk metals), transparent (very low dielectrically lossy materials) and absorbers (moderate to high dielectrically lossy materials). It is well recognized that bulk metals are opaque to microwaves and are good reflectors at room temperature; this property is used in radar detection. However, as we will see in the subsequent sections, metals in powder form are very good absorbers of microwaves and get heated very effectively.

Further, bulk metals, if pre-heated to moderate temperatures $\left(\sim 500^{\circ} \mathrm{C}\right)$, also become good microwave absorbers. Most other materials are either transparent or absorb microwaves to varying degrees at an ambient temperature depending upon their inherent electrical and magnetic properties. The degree of the microwave absorption and consequent heating profile changes dramatically with the rise in temperature. Microwave heating is material dependent; therefore only those materials that couple in the microwave field will get heated and the rate of heating will depend upon their degree of absorption, which is a function of various factors including the dielectric loss (insulators), magnetic properties (metals), grain size, porosity, frequency, electrical conductivity, etc. [89]. Microwaves, like any other type of electromagnetic radiation, have electrical and magnetic field components, amplitude, phase angle, and the ability to propagate, that is to transfer energy from one point to another. These properties govern the interaction of microwaves with materials and produce heating in some of them. Depending on the electrical and magnetic properties of the material, their interaction with microwaves can be classified as one of three types [98].

Transparent: Microwaves penetrate and are transmitted through the material completely with no energy transfer occurring (Fig. 14a). These materials are known as low-loss insulators.
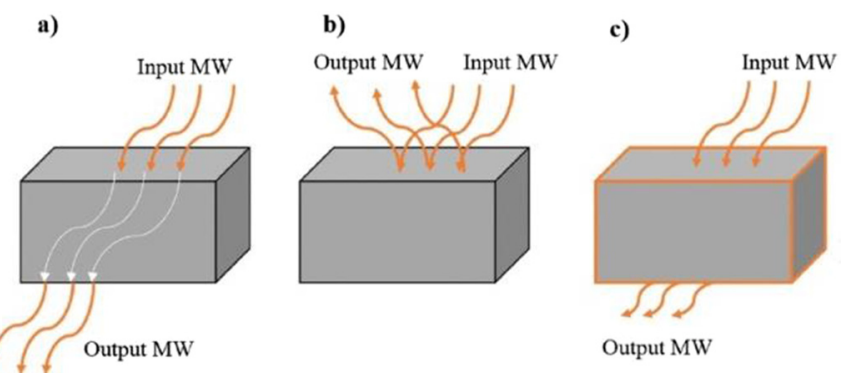

Fig. 14. Effect of microwaves on the processed material.

Opaque: Microwaves are reflected with no penetration into the material and no energy transfer. These are known as conductors (Fig. 14b) microwave energy.

Absorbent: Microwaves are absorbed by the material, and exchange of electromagnetic energy occurs (Fig. 14c). The amount of absorption depends on the dielectric properties of the material [98].

In order to explain the interaction of absorbing materials with microwave radiation and the energy transfer that occurs during this interaction, several physical mechanisms have been proposed. These mechanisms include bipolar rotation, resistive heating, electromagnetic heating, and dielectric heating. Depending on the material, the response to incoming radiation can be attributed to one mechanism or a combination of several of them.

The bipolar rotation occurs when electrically neutral polar molecules with positive and negatives charges are separated. Within a microwave field, these dipoles rotate in the direction of increasing amplitude. As a consequence of this rotation, friction among the molecules arises generating heat uniformly throughout the material.

Resistive heating occurs in conductors or semiconductors with relatively high electrical resistivity. These materials possess free electrons or a high ionic content where the ions receive enough freedom so current can be generated.

Electromagnetic heating takes place in materials with magnetic properties that are highly susceptible to external electromagnetic fields, such as those induced by microwave radiation. This type of heating can be described as a magnetic pole rotation of the material analogous to the rotation of polar molecules in oscillating electrical fields.

Dielectric heating is a mix of bipolar rotations and resistive heating. In microwave sintering of ceramics, this is the predominant mechanism. In the next section, the principles of dielectric heating in microwave-absorbent materials are described [98].

In contrast to traditional heating methods, microwave sintering of composites can offer certain advantages, such as energy efficiency, environmental friendliness, enhanced densification and a fine grain size due to the faster heating rates and the lower sintering temperature (Fig. 15). Additionally, uniform volumetric heating and smaller and equiaxed pores in the sintered green compacts and fine microstructure are added advantages of microwave 

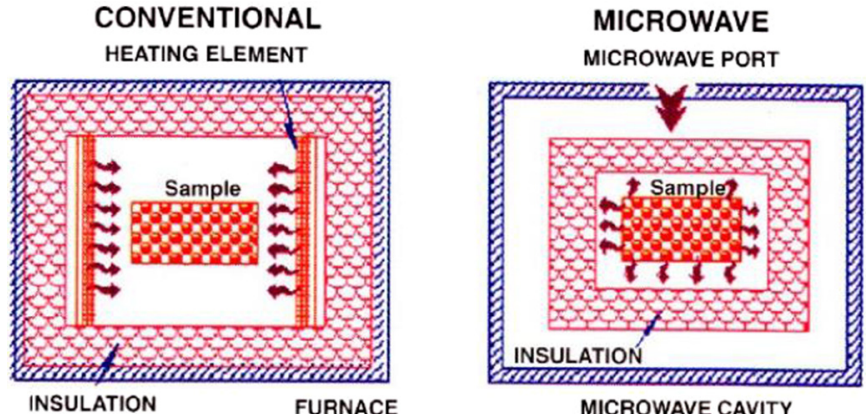

Fig. 15. Comparison between conventional and microwave sintering processes.

sintering. Hence, microwave sintering should result in improved mechanical properties and better product performance [125].

Alumina is the most common ceramic and has been widely used in microwave sintering research by many scientists working in the field. Because of its highly refractory nature, pure alumina is difficult to sinter to full densification unless suitable sintering aids or some special processing techniques are adopted. Many people have successfully sintered alumina to high densification in microwaves.

Nearly full sintering of the alumina using the microwave process has been achieved much faster and at a lower temperature than the conventional process. Small disc alumina samples microwave sintered at $1400{ }^{\circ} \mathrm{C}$, with no hold time, were $98 \%$ dense. In conventional heating, it requires at least $1600{ }^{\circ} \mathrm{C}$ and two hours of soaking time to achieve the same degree of densification accompanied by substantial grain growth. In general, in the microwaves nearly full density has been achieved at about $200^{\circ} \mathrm{C}$ less than the conventional temperature as shown in Figure 16 [89].

\subsubsection{Self-propagation high-temperature synthesis (SHS)}

Self-propagating high-temperature synthesis (SHS) or combustion synthesis (CS) is a rapidly developing research area. SHS materials are being used in various fields, including mechanical and chemical engineering, medical and bioscience, aerospace and nuclear industries. SHS is a self-sustained combustion process that yields practically valuable compounds and materials. Thus any selfsustained reactions, including synthesis from elemental powders, reactions of compounds, termites type reactions, combustion of porous solid reactive media in a gaseous oxidizer (also known as infiltration combustion), can be used for the SHS of advanced materials [126].

SHS allows workpieces to be produced from inorganic or organic compounds by combustion-like exothermic reactions in solids of different natures [127].

Self-propagating high-temperature synthesis or combustion synthesis has been used to synthesize refractory materials such as ceramics, ceramic composites, and intermetallic compounds. This technique is concerned with the ignition of a compressed powder mixture, in either

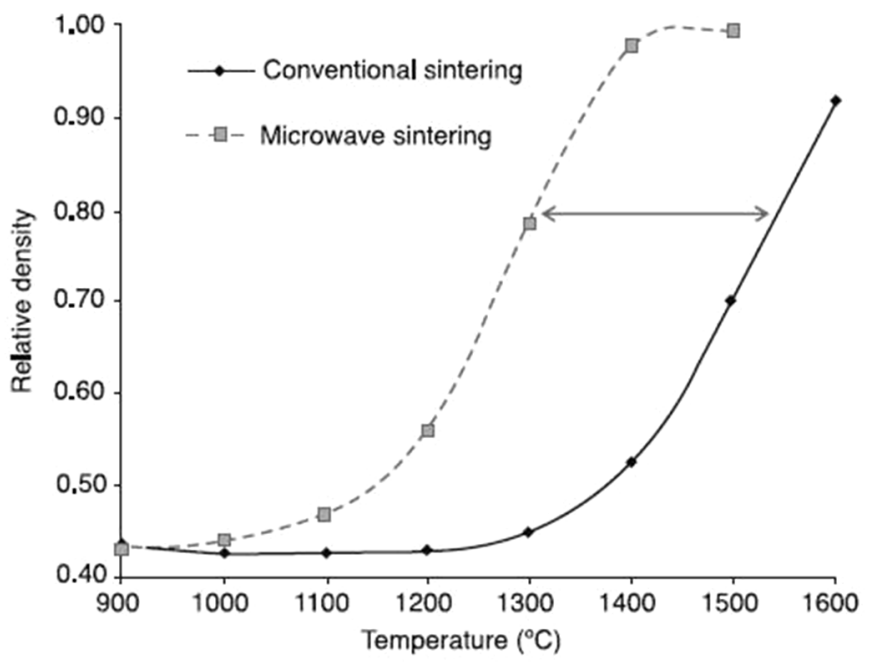

Fig. 16. Comparison between the specimens relative density when microwave or conventional sintering.

air or an inert atmosphere, producing chemical reactions with sufficient heat release (exothermic reaction) that the reaction becomes self-sustaining [128].

The earliest attempts at developing high-temperature structural ceramics started at the 1940s and were focused on BeO-based porcelains. During the 1950s, the efforts shifted toward cemented carbides (cermets). From the 1960s up to 2000s, the silicon-based ceramics such as silicon carbide $(\mathrm{SiC})$ and silicon nitride $\left(\mathrm{Si}_{3} \mathrm{~N}_{4}\right)$ were extensively developed due to their ability to retain strength up to 1300 $1400^{\circ} \mathrm{C}$ as well as their high resistance towards oxidation in air. However, some major drawbacks related to $\mathrm{SiC}$ and $\mathrm{Si}_{3} \mathrm{~N}_{4}$ (low electrical conductivity, low resistance toward the corrosion by water vapor and alkali cations, unstable mechanical properties under oxidation) were recognized. These drawbacks prevented the large-scale implementation of $\mathrm{SiC}$ and $\mathrm{Si}_{3} \mathrm{~N}_{4}$-based materials as high-temperature ceramics [129].

The self-propagating high-temperature synthesis (SHS) is a well-known method for the fabrication of several high-temperature ceramics, intermetallic and nanocomposite materials in a single-step of processing. The SHS technique has inherent advantages over the other methods that require high-temperature furnaces and longer processing times. Materials produced by the SHS process have advantages such as high purity of the products, low energy requirements, and relative simplicity. The exothermic heat generated during the SHS reaction is used for the completion of the chemical reaction. Once the reaction is initiated at a particular ignition temperature $\left(T_{i}\right)$, the combustion front propagated within the reactants travels at a particular combustion velocity $V_{c}$ to yield the final product. The feasibility of synthesizing a given compound or composite through this route and sustainability of the wave front propagation mainly depends on the extent of heat liberated by the exothermic reaction(s) and the heat dissipated from the system to the surroundings. The adiabatic temperature $T_{\mathrm{ad}}$, the theoretically calculated maximum rise in temperature under adiabatic conditions, 
is important for self-sustainability of a particular set of the exothermic reactions. Since most of the exothermic reactions are initiated at a temperature $\left(T_{i}\right)$ above the room temperature, the total enthalpy generated by the exothermic reaction is assumed to be consumed in increasing the temperatures of the products, and there is no heat loss to the surroundings [130].

The method of self-propagating high-temperature synthesis (SHS) provides the use of elemental powders as starting reagents while varying their granulometric composition over a wide range and has a relatively short production cycle and low power consumption. With its use, the compact materials with a metastable structure and a high degree of chemical purity can be produced owing to the unique effect of self-purification of synthetic products from dissolved and adsorbed impurities, which is caused by high values of the temperature and burning rate of various SHS systems [131].

High-temperature advanced ceramics (HTACs) have the potential for applications as special refractory materials or liners in foundries, as high-temperature shielding materials in aerospace engineering, gas turbine blades, cutting tools and as electrodes. To withstand the severe thermal requirements in the next generation of hypersonic vehicles particularly the sharp-shaped details, the materials should be able to sustain the operating temperatures approaching $2200^{\circ} \mathrm{C}$ resisting evaporation, erosion and oxidation. Diborides of transition metals such as $\mathrm{ZrB}_{2}$ and $\mathrm{HfB}_{2}$ are commonly referred to as suitable ceramics for their extremely high melting temperatures $\left(\mathrm{ZrB}_{2} 3040^{\circ} \mathrm{C}\right.$, $\left.\mathrm{HfB} 23250^{\circ} \mathrm{C}\right)$, solid state stability, good thermo-chemical, and thermo-mechanical properties. $\mathrm{ZrB}_{2}$ and $\mathrm{HfB}_{2}$-based composites reinforced with $\mathrm{SiC}$ and $\mathrm{TiC}$, indeed exhibit excellent refractoriness, high oxidation resistance, and are good potential candidates for such applications. Due to their extremely high melting points, covalent bonding, and low self-diffusion coefficient, these materials require very high sintering temperatures even higher than $2300{ }^{\circ} \mathrm{C}$ for densification. Sintering at high temperatures generally induces coarsening of the final microstructures, which leads to significant amounts of residual porosity and decreases the mechanical strength of sintered products. Different approaches have been investigated to optimize fabrication procedures and performances of these ceramics. Such as hot pressing, spark plasma processing, self-propagating high-temperature synthesis (SHS), sintering with additives, liquid phase sintering etc. However, the type and amount of grain boundary phases deriving from the sintering aids often deteriorate the high temperature properties, particularly when metal sintering aids were used. Also the grain boundary phases and grain size influence the properties to a large extent. All the processing techniques mentioned above have their own merits and demerits. Amongst all those processes, the SHS technique is more promising and challenging [130].

\section{Cutting conditions of ceramic tools}

High quality of mechanical parts can be achieved by the control of several parameters like cutting conditions, workpiece hardness, and cutting tool coating materials, leading to an improvement in mechanical properties like fatigue strength, corrosion resistance, and a reduction in friction and wearing [132]. High-speed machining leads to lower cutting forces, higher removal rates, and, therefore, to lower energy consumption [133].

The introduction of modern technologies can reduce the duration of the production cycle and reduce the cost of items, which can reduce its price or increase profit [1].

Working conditions are affected directly by the temperature; thus Bouzakis et al. [134] proposed a methodology based on theoretical and experimental tests to predict the performance of a coated cutting tool. The properties of PVD film, like fatigue strength and impact resistance at room and elevated temperatures with different cutting conditions such as cutting forces and feed were examined.

Altin et al. [135] presented investigation results experimentally on the influence of cutting speed on the tool life when machining Inconel 718 with silicon nitride based and ceramic tools with whiskers. They showed that that crater and flank wears are usually dominant wear types in ceramic square type (SNGN) inserts while flank and notch wear are dominant in round type (RNGN) inserts. Minimum flank wear was with SNGN tools at low cutting speeds while they see this with RNGN tools at high cutting speeds.

Surface roughness or surface quality is an important parameter that determines the post-manufacturing product quality. Tool wear, properties of the machined material, the vibration and sensitivity of the machine tool and adhesion of chips on the edges of the cutting tool (builtup edge (BUE)) are parameters affecting roughness [136]. Keblouti et al. [132] overviewed experimentally the influence of cutting parameters and coating materials on the performance of the cutting tool on the surface quality and cutting forces when turning of AISI 52100 steel with using ANOVA technique. Also, they compared between uncoated and coated (with $\mathrm{TiCN} / \mathrm{TiN}$ coating layer) cermet tools with constant substrate and geometry inserts. A mathematical model was created. They demonstrated that feed rate has a significant effect on the surface quality; however, cutting depth affects the cutting forces. Using a PVD coating a $(\mathrm{TiCN} / \mathrm{TiN})$ coated insert showed lower surface roughness compared to other tools.

The variety of machined component material hardness and the choice of cutting conditions have an influence on the tool life, cost and the quality of the products. Wang et al. [137] chose four ceramic ends milling tools and examined their performance. They included $\mathrm{Si}_{3} \mathrm{~N}_{4}$ and $\mathrm{Ti}$ $(\mathrm{CN})$ in machine hardened AISI H13 steel and other hardto-machine materials. They demonstrated that the value of the cutting forces of the ceramic end milling tools are less than the cutting forces of commercial cemented carbides, and the machined surface which is produced by ceramic end milling tools has a better surface roughness and longer tool life.

Xie et al. [138] proposed an uncoated tool with grooves $7-149 \mu \mathrm{m}$ in depth and $0.14-0.5 \mu \mathrm{m}$ in aspect ratio on tool rake surface along with the cutting chip, to explain the influence of micro-groove shape and size on the cutting 
temperature and cutting forces when turning titanium alloy under dry conditions. They fabricated the grooves by micro grinding with a diamond wheel (V-Tip). They discussed tool wear, cutting forces, temperature, and cutting performance. They demonstrated that the cutting forces and temperature decreased with grooved tools.

The optimum cutting speed of ceramic cutting tools is three to ten times larger than that of ordinary cemented carbide tools with the same geometrical parameters, which can improve the processing efficiency dramatically. The high hardness of workpiece materials will contribute to large cutting force and severe friction on the tool-chip interface. Additionally, the low thermal conductivity of workpiece materials will increase the cutting temperature, which further promotes tool wear and tool failure, such as adhesive wear, oxidation wear, diffusion wear, chipping and fracture [137]. Temperature near the rake face increases significantly when the depth of cut changes from 0.2 to $0.4 \mathrm{~mm}$. The increase in contact length between chip and rake face can be responsible, since it grows, together with uncut chip cross section [139].

Lima et al. [140] investigated the wear mechanisms; tool life and wear types of a SiAlON ceramic tool material composite in turning nickel-based alloy Inconel 751 within an argon and oxygen atmosphere. They used design of experiments techniques with variables such as tool life, tool material, SiAlON $\left(\mathrm{Si}_{3} \mathrm{~N}_{4} / \mathrm{Al}_{2} \mathrm{O}_{3}\right)$, whiskers $\left(\mathrm{Al}_{2} \mathrm{O}_{3} / \mathrm{SiC}_{\mathrm{w}}\right)$, mixed $\left(\mathrm{Al}_{2} \mathrm{O}_{3} / \mathrm{TiC}\right)$, cutting speed, tool geometry and gas cooling atmosphere with type dry cutting which is consisted with argon and oxygen. They demonstrated that the SiAlON is the best performance and secondly the whisker ceramic, because of the oxygen-rich atmosphere, the notch wear was accelerated especially at low cutting speed.

Yin et al. [141] studied the tool life and the cutting performance of an $\mathrm{Al}_{2} \mathrm{O}_{3} / \mathrm{TiC}$ micro-nano-composite ceramic tool in machining austenitic stainless steel. They demonstrated that wear resistance of an $\mathrm{Al}_{2} \mathrm{O}_{3} / \mathrm{TiC}$ micronano-composite was better than an alumina-based ceramic tool only. The ceramic tool failure is predicted by fatigue behavior.

Traditionally, cutting fluids have been widely used in machining operations in efforts to increase cooling and lubricity, and as a result enhances tool life and reduce process variability [142]. Many countries and foundations classified them as hazardous wastes, and impose even stricter controls if they contain oil and certain alloys. At the same time, the presence of coolant is necessary to enable the machining of hard to cut materials. Therefore many types of research tried to increase the cutting tool hardness or design self lubricating materials and finally designing cutting tools with a textured pattern.

Dry or wet machining is a major decision that affects cutting conditions. Sugihara et al. [143] proposed a new CBN cutting tool with a textured flank face to increase the efficiency of cutting tools with coolant. They designed the cutting tool as based on experiments with a wide range of cutting conditions in high-speed machining of Inconel 718. Ariff et al. [144] studied parameters affecting the machining of T6061 aluminum alloy using silicon nitride $\left(\mathrm{Si}_{3} \mathrm{~N}_{4}\right)$ inserts cutting tool material by machining dry and with coolant.

The tool wear of $\mathrm{Si}_{3} \mathrm{~N}_{4}$ was investigated to obtain the optimum cutting conditions for both dry and coolant machining. This showed that dry machining with smaller parameters offers lower wear rates varying from 37 to $48 \%$ depending on cutting speed. The optimum conditions for machining T6061 aluminum alloy by $\mathrm{Si}_{3} \mathrm{~N}_{4}$ is $518 \mathrm{~m} / \mathrm{min}$. They also showed that the dry machining of Al6061 aluminum by $\mathrm{Si}_{3} \mathrm{~N}_{4}$ instrument in high speeds was optimal.

Dhang et al. [145] discussed another method of coolant called near dry. Through their work they studied the dry and near dry intermittent orthogonal cutting of AISI 1045 steel by using an uncoated P30 grade cemented tungsten carbide tool with different surface textures applied on the rake surface. They enhanced the surface roughness on the specimen and decreased the cutting forces on the cutting tool.

In the past, machining parameters were based on the experience of the machine operator [1]. Today it is important to create suitable equations that show the optimized machined conditions, and they must be related to the cutting tool material, geometry and be concerned with the surface roughness of the machined component. Evaluating cutting tool performance and predicting its durability are very important in choosing the proper cutting tool material. Therefore Baska et al. [146] compared various milling end mills cutters in the machining of hardened steel (DIN X 210 Cr12) to obtain their durability. They used the results to enhance the performance of the end mill. Figure 17 shows the capabilities of various cutting tool materials [147].

Within the machining processes cutting forces influence the cutting performance and therefore the cost of the product. Because tool cutting edges are made to be sharp enough to cut the alloys and metals to be machined they suffer from high stresses during the cutting process. Therefore much research is carried out to determine perfect tool geometry [148]. Tian et al. [133] studied the cutting forces, tool wear, morphologies and mechanical failure with a wide range of cutting speed (600- $3000 \mathrm{~m} / \mathrm{min})$. They demonstrated that the cutting force decreased and then increased with increasing cutting speed. The notch type wear existed with relatively low cutting speeds $(600-1000 \mathrm{~m} / \mathrm{min})$ but with increasing the cutting speed the notch wear decreases. Notch wear on the flank face was greater in and milling than that in face milling under the same conditions, but surface roughness for and milling was following then in face milling.

According to Ma et al. [149], they examined the residual stress and discussed the cutting forces, temperature, and cutting conditions. They measured the residual stresses after machining and also they studied the influence of mechanical and thermal loads on them. Large feed reduces the effect of the cutting forces on the residual stresses.

Vereschaka et al. [150] designed a damping device (Fig. 18) which works in minimizing peak stresses occurring through the cutting process and improves the performance of ceramic tools. The damper device was made of steel C45 with hardness less than the material machined. It reduced the peak stresses and they studied the proposed 


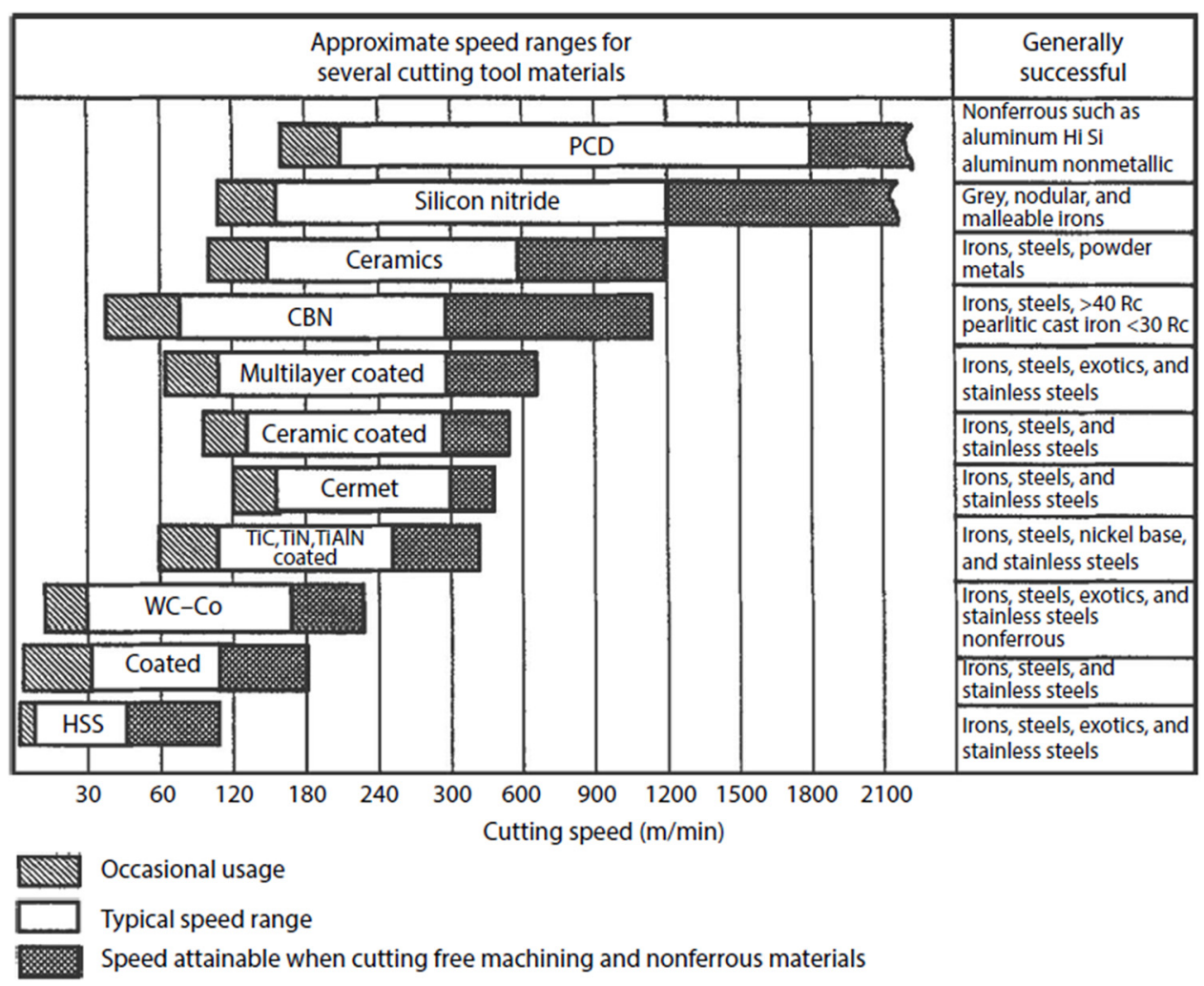

Fig. 17. Ability of tool material with cutting speed on machining several materials [147].

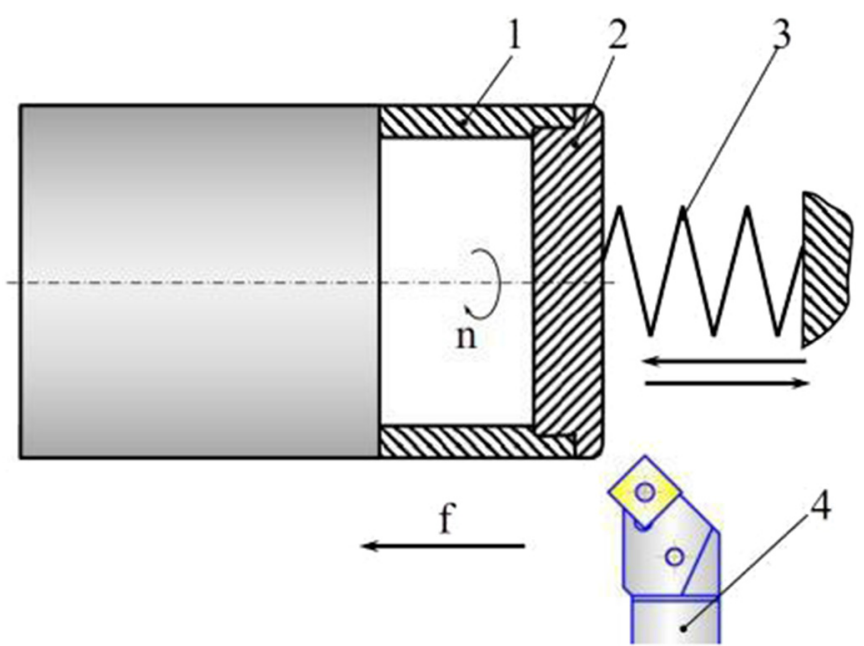

Fig. 18. Principal scheme of damping device; (1) workpiece being machined; (2) disc damping peak stresses in cutting with the tool; (3) damper of extension vibrations of a workpiece; (4) cutting tool equipped with cutting inserts of cutting ceramic.

nanostructured multi-layered coatings. It concluded that damping peak stresses enhance the reliability of ceramic and carbide tools.

\section{Conclusions}

One of the main problems concerning machining is associated with the cutting tool and its quality. It is often required to fabricate a tool with high hardness and good mechanical properties, having suitable performance and reasonable life. A dry machining capability is preferred, without ignoring the cost related issues as well as requirements on the tool-fabrication method. Taking into account of those factors, cutting ceramics have been widely investigated: mechanical and tribological properties have been assessed and further researched in order to obtain optimal properties of ceramic tools and to enhance cutting tool performance; several methods of ceramics manufacturing were also investigated. With a high degree of probability, it can be assumed that in 10-15 years time ceramic cutting-tools could take the place of a modern carbide tool. Already, some studies showed that the cutting forces when using ceramic tools are less than that when using carbide tools. In addition, ceramics provides better surface quality and longer tool life. Excellent mechanical properties of ceramics have been obtained using advanced technologies, including hardness, bending-strength and crack resistance, these allowing its uses with success in the industry.

The hot-pressed sintering and spark plasma sintering are preferential methods of manufacturing cutting tools. Nevertheless, non-contact methods such as microwave and some SPS sintering are also being actively developed. Each of them is characterized by its properties achievable, sintering mechanisms, merits or disadvantages. Some comparison has been made among those technologies to identify the most suitable process for particular cutting tools. Indeed, enhancement of cutting tool performance of 
the created tools with low cost is an immense priority. Optimizing tool design is one of the economical ways for advancing the cutting tools without need to change the tool material while still improving the tribological and mechanical properties, through changing the geometry of the tools. It is concluded that creating specific tables for proper cutting conditions for each tool material saves time and cost, while tool life and surface roughness can still be improved. It is also concluded that creating new cutting tools or choosing cutting tool materials for a specific cutting process is dependent largely on several parameters which mutually interact with each other and each of which cannot be singled out easily.

In summary, cutting tools made of ceramics are very promising, although the mechanical properties still need to be enhanced. Creating new cutting tools with better mechanical and tribological properties, further developing tool designs, and creating more accurate equations for describing cutting conditions, are the work to be addressed further, representing a future trend.

\section{Funding}

This work was carried out with the financial support from the Russian Foundation for Basic Research (scientific project No. 19-08-00899).

\section{References}

1. M. Hrelja, S. Klancnik, T. Irgolic, M. Paulic, J. Balic, M. Brezocnik, Turning parameters optimization using particle swarm optimization, J. Proc. Eng. 69 (2014) 670-677

2. H.A. El-Hofy, Advanced Machining Processes, McGrawHill, New York, USA, 2005

3. R. Baptista, J.F.A. Simoes, Three and five axes milling of sculptured surfaces, J. Mat. Process. Technol. 103 (2000) 398-403

4. K. Hamdy, M.K. Mohamed, G. Abouelmagd, New electrode profile for machining of internal cylindrical surfaces by electrochemical drilling, Int. J. Control. Autom. Syst. 2 (2013) 2165-8277

5. T. Wagner, High rate electrochemical dissolution of ironbased alloys in $\mathrm{NaCl}$ and $\mathrm{NaNO}_{3}$ electrolytes, Ph.D. Thesis, School of Chemistry, University of Stuttgart, Germany, 2002

6. A.M. Ibrahim, Investigation of Some Electrochemical Machining Parameters for Internal Conical Shapes, M. Sc. Thesis, Faculty of Engineering, Minia University, Egypt, 2011

7. J.A. McGeough, Principles of Electrochemical Machining, Chapman and Hall Ltd., London, UK, 1974

8. C.F. Gutiérrez-González, M. Suarez, S. Pozhidaev, S. Rivera, P. Peretyagin, W. Solís, L.A. Díaz, A. Fernandez, R. Torrecillas, Effect of $\mathrm{TiC}$ addition on the mechanical behavior of $\mathrm{Al}_{2} \mathrm{O}_{3}$ - $\mathrm{SiC}$ whiskers composites obtained by SPS, J. Eur. Ceram. Soc. 36 (2016) 2149-2152

9. W. Grzesik, Cutting tool materials, Adv. Mach. Processes Metallic Mater. 2 (2017) 35-63

10. G.T. Smith, Cutting Tool Technology, Springer, London, UK 2008
11. B. Zhao, H. Liu, C. Huang, J. Wang, M. Cheng, Fabrication and mechanical properties of $\mathrm{Al}_{2} \mathrm{O}_{3}-\mathrm{SiC}_{\mathrm{w}}-\mathrm{TiC}_{\mathrm{np}}$ ceramic tool material, Ceram. Int. 43 (2017) 10224-10230

12. M. Mohammadpour, P. Abachi, K. Pourazarang, Effect of cobalt replacement by nickel on functionally graded cemented carbonitrides, Int. J. Refract. Met. Hard Mater. 30 (2012) 42-47

13. E.D. Whitney, Ceramic Cutting Tools: Materials, Development, and Performance, William Andrew Publishing, Norwich, USA, 1995

14. T. Kitagawa, A. Kubo, K. Maekawa, Temperature and wear of cutting tools in high-speed machining of Incone1718 and Ti-6A1-6V-2Sn, Wear 202 (1997) 142-148

15. L. Li, N. He, M. Wang, Z.G. Wang, High-speed cutting of Inconel 718 with coated carbide and ceramic inserts, J. Mater. Process. Technol. 129 (2002) 127-130

16. G. Schneider Jr., Cutting Tools Application, 2009, http:// www.toolingandproduction.com/web/home.php

17. J. Zhao, 25-the use of ceramic matrix composites for metal cutting applications, Adv. Ceram. Matrix Compos. 2 (2014) 623-654

18. D.H. Jack, Ceramic cutting tool materials, Mater. Des. 7 (1986) 267-273

19. J. Gonzalez-Julian, J. Schneider, P. Miranzo, M.I. Osendi, M. Belmonte, Enhanced tribological performance of silicon nitride-based materials by adding carbon nanotubes, J. Am. Ceram. Soc. 94 (2011) 2542-2548

20. G.D. Quinn, J. Salem, I. Bar-on, K. Cho, M. Fotey, H. Fang, Fracture toughness of advanced ceramics at room temperature, J. Res. Natl. Inst. Stand. Technol. 97 (1992) 579-607

21. M. Cheng, H. Lia, B. Zhao, C. Huang, P. Yao, B. Wang, Mechanical properties of two types of $\mathrm{Al}_{2} \mathrm{O}_{3} / \mathrm{TiC}$ ceramic cutting tool material at room and elevated temperatures, Ceram. Int. 43 (2017) 13869-13874

22. E.D. Whitney, Ceramic Cutting Tools: Materials, Development, and Performance, William Andrew Publishing, Norwich, USA, 1995

23. D.A. Stephenson, J.S. Agapiou, Metal Cutting Theory and Practice, 3rd edn., CRC Press Taylor \& Francis Group, New York, USA, 2016

24. Z. Yin, C. Huang, B. Zou, H. Liu, H. Zhu, J. Wang, Study of the mechanical properties, strengthening and toughening mechanisms of $\mathrm{Al}_{2} \mathrm{O}_{3} / \mathrm{TiC}$ micro-nano-composite ceramic tool material, Mater. Sci. Eng. A. 577 (2013) 9-15

25. J. Barry, G. Byrne, Cutting tool wear in the machining of hardened steels Part I: alumina/TiC cutting tool wear, Wear 247 (2001) 139-151

26. Y.L. Dong, F.M. Xu, X.L. Shi, C. Zhang, Z.J. Zhang, J.M. Yang, Y. Tan, Fabrication and mechanical properties of nano-/micro-sized $\mathrm{Al}_{2} \mathrm{O}_{3} / \mathrm{SiC}$ composites, Mat. Sci. Eng. A. 501 (2009) 49-54

27. H. Awaji, S.-M. Choi, E. Yagi, Mechanisms of toughening and strengthening in ceramic-based nanocomposites, Mech. Mater. 34 (2002) 411-422

28. V. Bushlya, J. Zhou, P. Avdovic, J.-E. Stahl, Wear mechanisms of silicon carbide-whisker-reinforced alumina $\left(\mathrm{Al}_{2} \mathrm{O}_{3}-\mathrm{SiCw}\right)$ cutting tools when high-speed machining aged Alloy 718, Int. J. Adv. Manuf. Technol. 68 (2013) 1083-1093

29. Y.M. Ko, W.T. Kwona, Y.-W. Kim, Development of $\mathrm{Al}_{2} \mathrm{O}_{3}$-SiC composite tool for machining application, Ceram. Int. 30 (2004) 2081-2086 
30. L. Xuefei, L. Hanlian, H. Chuanzhen, Z. Bin, Z. Longwei, High-temperature mechanical properties of $\mathrm{Al}_{2} \mathrm{O}_{3}$-based ceramic tool material toughened by $\mathrm{SiC}$ whiskers and nanoparticles, Ceram. Int. 43 (2017) 1160-1165

31. Z. Li, J. Zhao, J. Sun, F. Gong, X. Ni, Reinforcement of $\mathrm{Al}_{2} \mathrm{O}_{3} / \mathrm{TiC}$ ceramic tool material by multi-layer graphene, Ceram. Int. 43 (2017) 11421-11427

32. D. Wang, C. Xue, Y. Cao, J. Zhao, Fabrication and cutting performance of an $\mathrm{Al}_{2} \mathrm{O}_{3} / \mathrm{TiC} / \mathrm{TiN}$ ceramic cutting tool in turning of an ultra-high-strength steel, Int. J. Adv. Manuf. Technol. 91 (2017) 1967-1976

33. J. Liu, H. Yan, K. Jiang, Mechanical properties of graphene platelet-reinforced alumina ceramic composites, Ceram. Int. 39 (2013) 6215-6221

34. J.W. An, D.H. You, D.S. Lim, Tribological properties of hot-pressed alumina - CNT composites, Wear 255 (2003) 677-681

35. B.I. Smirnov, V.I. Nikolaev, T.S. Orlova, V.V. Shpeizman, A.R. Arellano-Lopez, K.C. Goretta, D. Singh, J.L. Routbort, Mechanical properties and microstructure of an $\mathrm{Al}_{2} \mathrm{O}_{3}$-SiC-TiC composite, Mat. Sci. Eng. A 242 (1998) 292-295

36. W. Liu, Q. Chu, R. He, M. Huang, H. Wu, Q. Jiang, J. Chen, X. Deng, S. Wu, Preparation and properties of TiAlN coatings on silicon nitride ceramic cutting tools, Ceram. Int. 44 (2018) 2209-2215

37. P. Svec, A. Brusilová, J. Kozánková, Effect of microstructure and mechanical properties on wear resistance of silicon nitride ceramics, Mater. Eng. 16 (2008) 34-40

38. D.-H. Choi, B.-K. Moon, R.-J. Sung, S.-H. Kim, K. Niihara, Mechanical and thermal properties of silicon nitride hot pressed with adding rare-earth oxides, Mater. Sci. Forum 486-487 (2005) 181-184

39. L. Kvetkova, A. Duszova, P. Hvizdos, J. Dusza, P. Kun, C. Balazsi, Fracture toughness and toughening mechanisms in graphene platelet reinforced $\mathrm{Si}_{3} \mathrm{~N}_{4}$ composites, Scr. Mater. 66 (2012) 793-796

40. A.S. Kumar, A.R. Durai, T. Sornakumar, Development of alumina-ceria ceramic composite cutting tool, Int. J. Refract. Met. Hard Mater. 22 (2004) 17-20

41. X. Tian, J. Zhao, N. Zhu, Y. Dong, J. Zhao, Preparation and characterization of $\mathrm{Si}_{3} \mathrm{~N}_{4} /(\mathrm{WTi}) \mathrm{C}$ nano-composite ceramic tool materials, Mater. Sci. Eng. A. 596 (2014) 255-263

42. G.M. Zheng, J. Zhao, Y.H. Zhou, Z.J. Gao, X.B. Cui, A.H. $\mathrm{Li}$, Fabrication and characterization of Sialon-Si $\mathrm{N}_{4}$ graded nano-composite ceramic tool materials, Compos. Part B 42 (2011) 1813-1820

43. G. Zheng, J. Zhao, Z. Gao, Q. Cao, Cutting performance and wear mechanisms of Sialon- $\mathrm{Si}_{3} \mathrm{~N}_{4}$ graded nano-composite ceramic cutting tools, Int. J. Adv. Manuf. Technol. 58 (2012) 19-28

44. G. Tu, S. Wu, J. Liu, Y. Long, B. Wang, Cutting performance and wear mechanisms of Sialon ceramic cutting tools at high-speed dry turning of gray cast iron, Int. J. Refract. Met. Hard Mater. 54 (2016) 330-334

45. X. Tian, J. Zhao, Z. Gong, Y. Dong, Effect of cutting speed on cutting forces and wear mechanisms in high-speed face milling of Inconel 718 with Sialon ceramic tools, Int. J. Adv. Manuf. Technol. 69 (2013) 2669-2678

46. Z. Hao, Y. Fan, J. Lin, F. Ji, X. Liu, New observations on wear mechanism of self-reinforced SiAlON ceramic tool in milling of Inconel 718, Arch. Civil Mech. Eng. 17 (2017) 467-474
47. Y. Cheng, Y. Zhang, T. Wan, Z. Yin, J. Wang, Mechanical properties and toughening mechanisms of graphene platelets reinforced $\mathrm{Al}_{2} \mathrm{O}_{3} / \mathrm{TiC}$ composite ceramic tool materials by microwave sintering, Mat. Sci. Eng. A 680 (2017) 190-196

48. W-M. Guo, J.-J. Yu, M. Xiong, S.-H. Wu, H.-T. Lin, Hightoughness $\mathrm{Lu}_{2} \mathrm{O}_{3}$-doped $\mathrm{Si}_{3} \mathrm{~N}_{4}$ ceramics by seeding, Ceram. Int. 42 (2016) 6495-6499

49. S.L. Casto, E.L. Valvo, E. Lucchini, S. Maschio, V.F. Ruisi, Wear rates and wear mechanisms of alumina-based tools cutting steel at a low cutting speed, Wear 208 (1997) $67-72$

50. S.J. Lee, S. Baek, Effect of $\mathrm{SiO}_{2}$ content on the microstructure, mechanical and dielectric properties of $\mathrm{Si}_{3} \mathrm{~N}_{4}$ ceramics, Ceram. Int. 42 (2016) 9921-9925

51. B. Bitterlich, S. Bitsch, K. Friederich, SiAlON based ceramic cutting tools, J. Eur. Ceram. Soc. 28 (2008) 989-994

52. S. Gandotra, J. Singh, S.S. Gill, Investigation of wear behavior on coated and non-coated carbide inserts subjected to low temperature treatment, J. Metall. Eng. 1 (2011) 1-16

53. S. Kumar, N.K. Khedkar, B. Jagtap, T.P. Singh, The effects of cryogenic treatment on cutting tools, IOP Conf. Series: Mater. Sci. Eng. 225 (2017) 1-9

54. J. Dusza, J. Morgiel, A. Duszová, L. Kvetková, M. Nosko, P. Kun, C. Balázsi, Microstructure and fracture toughness of $\mathrm{Si}_{3} \mathrm{~N}_{4}+$ graphene platelet composites, J. Eur. Ceram. Soc. 32 (2012) 3389-3397

55. C.H. Xu, Y.M. Feng, R.B. Zhang, X. Xiao, G.T. Yu, Wear behavior of $\mathrm{Al}_{2} \mathrm{O}_{3} / \mathrm{Ti}(\mathrm{C}, \mathrm{N}) / \mathrm{SiC}$ new ceramic tool material when machining tool steel and cast iron, J. Mater. Process. Technol. 209 (2009) 4633-4637

56. Y. Liu, C. Huang, B. Zou, H. Liu, G. Liu, High-temperature flexural strength and reliability of $\mathrm{Ti}\left(\mathrm{C}_{5} \mathrm{~N}_{5}\right)-\mathrm{TiB}_{2^{-}}$ $\left(\mathrm{W}_{7} \mathrm{Ti}_{3}\right) \mathrm{C}$ composite cermet tool material, Ceram. Int. 43 (2017) 12511-12518

57. G. Zhao, C. Huang, H. Liu, L. Xu, X. Chong, B. Zou, H. Zhu, A study on in situ growth of $\mathrm{TaC}$ whiskers in $\mathrm{Al}_{2} \mathrm{O}_{3}$ matrix powder for ceramic cutting tools, Mater. Res. Bull. 47 (2012) 2027-2031

58. Y.M. Ko, W.T. Kwona, Y.-W. Kim, Development of $\mathrm{Al}_{2} \mathrm{O}_{3^{-}}$ $\mathrm{SiC}$ composite tool for machining application, Ceram. Int. 30 (2004) 2081-2086

59. B.L. Strahin, G.L. Doll, Tribological coatings for improving cutting tool performance, Surf. Coat. Technol. 336 (2018) $117-122$

60. J.M. Zhou, V. Bushlya, J.E. Stahl, An investigation of surface damage in the high speed turning of Inconel 718 with use of whisker reinforced ceramic tools, J. Mater. Process. Technol. 212 (2012) 372-384

61. S.L. Casto, E.L. Valvo, E. Lucchini, S. Maschio, M. Piacentini, V.F. Ruisi, Ceramic materials wear mechanisms when cutting nickel-based alloys, Wear 225-229 (1999) 227-233

62. X. Maohua, H. Ning, L. Liang, Modeling notch wear of ceramic tool in high-speed machining of nickel-based superalloy, J. Wuhan Univ. Technol. Mater. Sci. Ed. 25 (2010) 78-83

63. P. Hvizdos, J. Dusza, C. Balázsi, Tribological properties of $\mathrm{Si}_{3} \mathrm{~N}_{4}$-graphene nanocomposites, J. Eur. Ceram. Soc. 33 (2013) 2359-2364

64. I. Schulz, M. Herrmann, I. Endler, I. Zalite, B. Speisser, J. Kreusser, Nano $\mathrm{Si}_{3} \mathrm{~N}_{4}$ composites with improved tribological properties, Lubric. Sci. 21 (2009) 69-81 
65. L.N. López de Lacalle, A. Lamikiz, J. Fernández de Larrinoa, I. Azkona, Advanced Cutting Tools, Springer, London, UK 2011

66. T. Chung-Cheng, H. Hong, Comparison of the tool life of tungsten carbide coated by multi-layer TiCN and TiALCN for end mills using Taguchi method, J. Mater. Process. Technol. 123 (2002) 1-4

67. K.-D. Bouzakis, N. Michailidis, G. Skordaris, E. Bouzakis, D. Biermann, R. M'Saoubi, Cutting with coated tools: coating technologies, characterization methods and performance optimization, CIRP Ann. Manuf. Technol. 61 (2012) 703-723

68. S. Koseki, K. Inoue, H. Usuki, Damage of physical vapor deposition coatings of cutting tools during alloy 718 turning, Prec. Eng. 44 (2016) 41-54

69. S. Grigoriev, A. Metel, Nanostructured thin films and nanodispersion strengthened coatings, NATO Sci. Ser. II: Math. Phys. Chem. 155 (2004) 47-154

70. A.S. Vereschaka, S.N. Grigoriev, V.P. Tabakov, E.S. Sotova, A.A. Vereschaka, M.Y. Kulikov, Improving the efficiency of the cutting tool made of ceramic when machining hardened steel by applying nano-dispersed multi-layered coatings, Key Eng. Mater. 581 (2014) 68-73

71. A.A. Vereschaka, S.N. Grigoriev, M.A. Volosova, A. Batako, A.S. Vereschaka, N.N. Sitnikov, A.E. Seleznev, Nano-scale multi-layered coatings for improved efficiency of ceramic cutting tools, Int. J. Adv. Manuf. Technol. 90 (2017) 27-43

72. J. Liu, C. Ma, G. Tu, Y. Long, Cutting performance and wear mechanism of Sialon ceramic cutting inserts with TiCN coating, Surf. Coat. Technol. 307 (2016) 146-150

73. G. Gurdial Blugan, C. Strehler, M. Vetterli, B. Ehrle, R. Duttlinger, P. Blösch, J. Kuebler, Performance of lightweight coated oxide ceramic composites for industrial high speed wood cutting tools: a step closer to market, Ceram. Int. 43 (2017) 8735-8742

74. S. Chinchanikar, S.K. Choudhury, Characteristic of wear, force and their inter-relationship: in process monitoring of tool within different phases of the tool life, Proc. Mater. Sci. 5 (2014) 1424-1433

75. Y. Isik, The performance evaluation of ceramic and carbide cutting tools in machining of austemepered ductile irons, Uludag University J. Faculty Eng. 19 (2014) 67-76

76. A. Vereschaka, S. Grigoriev, Wear 378-379 (2017) 43-57

77. Y. Long, J. Zeng, S. Wu, Cutting performance and wear mechanism of Ti-Al-N/Al-Cr-O coated silicon nitride ceramic cutting inserts, Ceram. Int. 40 (2014) 9615-9620

78. K.K. Gajrani, M.R. Sankar, State of the art on micro to nano-textured cutting tools, Mater. Today Proc. 4 (2017) 3776-3785

79. Y. Feng, J. Zhang, L. Wang, W. Zhang, Y. Tian, X. Kong, Fabrication techniques and cutting performance of microtextured selflubricating ceramic cutting tools by in-situ forming of $\mathrm{Al}_{2} \mathrm{O}_{3}$-TiC, Int. J. Refract. Met. Hard Mater. 68 (2017) 121-129

80. Y. Lian, J. Deng, G. Yan, H. Cheng, J. Zhao, Preparation of tungsten disulfide $\left(\mathrm{WS}_{2}\right)$ soft-coated nano-textured selflubricating tool and its cutting performance, Int. J. Adv. Manuf. Technol. 68 (2013) 2033-2042

81. T. Sugihara, T. Enomoto, Improving anti-adhesion in aluminum alloy cutting by micro strip texture, Prec. Eng. 36 (2012) 229-237
82. Y. Xing, J. Deng, J. Zhao, G. Zhang, K. Zhang, Cutting performance and wear mechanism of nanoscale and microscale textured $\mathrm{Al}_{2} \mathrm{O}_{3} / \mathrm{TiC}$ ceramic tools in dry cutting of hardened steel, Int. J. Refract. Met. Hard Mater. 43 (2014) $46-58$

83. N. Kawasegi, H. Sugimori, H. Morimoto, N. Morita, I. Horid, Development of cutting tools with microscale and nanoscale textures to improve frictional behavior, Prec. Eng. 33 (2009) 248-254

84. P. Rathod, S. Aravindan, R.P. Venkateswara, Performance Evaluation of Novel Micro-textured Tools in Improving the Machinability of Aluminum Alloy (Al 6063), Proc. Technol. 23 (2016) 296-303

85. P. Rathod, S. Aravindan, R.P. Venkateswara, Performance evaluation of novel micro-textured tools in improving the machinability of aluminum alloy (Al 6063), Proc. Technol. 23 (2016) 296-303

86. V. Kuzin, S. Grigoriev, Method of investigation of the stressstrain state of surface layer of machine elements from a sintered nonuniform material, Appl. Mech. Mater. 486 (2014) $32-35$

87. G. Wu, C. Xu, G. Xiao, M. Yi, Z. Chen, L. Xu, Selflubricating ceramic cutting tool material with the addition of nickel coated CaF2 solid lubricant powders, Int. J. Refract. Met. Hard Mater. 56 (2016) 51-58

88. X. Cui, J. Guo, J. Zheng, Optimization of geometry parameters for ceramic cutting tools in intermittent turning of hardened steel, Mater. Des. 92 (2016) 424-437

89. D. Agrawal, Microwave sintering of ceramics, composites and metal powders, Woodhead Publishing Limited, USA, 2010

90. J. Cinert, Study of Mechanisms of the Spark Plasma Sintering Technique, PHD, Czech Technical University, Prague, Czech Republic, 2018

91. W.R. Matizamhuka, Spark plasma sintering (SPS) - an advanced sintering technique for structural nanocomposite materials, J. S. Afr. Inst. Min. Metall. 116 (2016) 1171-1180

92. G.C. Wei, A. Hecker, D.A. Goodman, Translucent polycrystalline alumina with improved resistance to sodium attack, J. Am. Ceram. Soc. 84 (2001) 2853-2862

93. N. Saheb, Z. Iqbal, A. Khalil, A.S. Hakeem, N. Al-Aqeeli, T. Laoui, A. Al-Qutub, R. Kirchner, Spark plasma sintering of metals and metal matrix nanocomposites: a review, J. Nanomater. (2012)

94. Z.A. Munir, U. Anselmi-Tamburini, M. Ohyanagi, The effect of electric field and pressure on the synthesis and consolidation of materials: A review of the spark plasma sintering method, J. Mater. Sci. 41 (2006) 763-777

95. B.-K. Yoon, E.Y. Chin, S.-J.L. Kang, Dedensification during Sintering of $\mathrm{BaTiO}_{3}$ Caused by the Decomposition of Residual $\mathrm{BaCO}_{3}$, J. Am. Ceram. Soc. 91 (2008) 4121-4124

96. M. Tokita, Chapter 11.2.3-Spark Plasma Sintering (SPS) Method, Systems, and Applications, Handbook of Advanced Ceramics, 2nd edn., Materials, Applications, Processing, and Properties, 2013, 1149-1177

97. M. Suárez, A. Fernández, J. Menéndez, R. Torrecillas, H. Kessel, J. Hennicke, R. Kirchner, T. Kessel, Challenges and opportunities for spark plasma sintering: a key technology for a new generation of materials. In Sintering Applications, 1st edn.; B. Ertug, Ed., InTech, Rijeka, Croatia, 2013

98. A. Borrell, M.D. Salvador, Chapter 1: Advanced Ceramic Materials Sintered by Microwave Technology, Sintering Technology - Method and Application, Intech open, 2018 
99. K. Gołombek, L.A. Dobrzanski, Hard and wear resistance coatings for cutting tools, J. Achiev. Mater. Manuf. Eng. 24 (2007) 107-110

100. E. Gevorkyan, S. Lavrynenko, M. Rucki, Z. Siemiatkowski, M. Kislitsa, Ceramic cutting tools out of nanostructured refractory compounds, Int. J. Refract. Met. Hard Mater. 68 (2017) 142-144

101. M. Li, C. Huang, B. Zhao, H. Liu, J. Wang, Z. Liu, Mechanical properties and microstructure of $\mathrm{Al}_{2} \mathrm{O}_{3}-\mathrm{TiB}_{2^{-}}$ $\mathrm{TiSi}_{2}$ ceramic tool material, Ceram. Int. 43 (2017) 1419214199

102. L. Wang, H. Liu, C. Huang, X. Liu, B. Zou, Mechanical properties and microstructure of $\mathrm{TiN}^{-\mathrm{TiB}_{2}}$ composite ceramic cutting tool material, Mater. Sci. Forum. 800801 (2014) 430-434

103. B. Zou, C. Huang, J. Song, Z. Liu, L. Liu, Y. Zhao, Effects of sintering processes on mechanical properties and microstructure of $\mathrm{TiB}_{2}-\mathrm{TiC}+8 \mathrm{wt} \%$ nano-Ni composite ceramic cutting tool material, Mater. Sci. Eng. A. 540 (2012) 235244

104. Y. Fazhan, M. Guangyao, Z. Jun, A. Xing, Fabrication of WC matrix composite tool material and its cutting performance in machining titanium alloys, Tsinghua Sci. Technol. 14 (2009) 75-78

105. S.P. Taguchi, S. Ribeiro, Silicon nitride oxidation behavior at 1000 and $1200^{\circ} \mathrm{C}, \mathrm{J}$. Mater. Process. Technol. 147 (2004) 336-342

106. P. Rutkowski, L. Stobierski, D. Zientara, L. Jaworska, P. Klimczyk, M. Urbanik, The influence of the graphene additive on mechanical properties and wear of hot-pressed $\mathrm{Si}_{3} \mathrm{~N}_{4}$ matrix composites, J. Eur. Ceram. Soc. 35 (2015) 87-94

107. Z. Yin, C. Huang, B. Zou, H. Liu, H. Zhu, J. Wang, Effects of particulate metallic phase on microstructure and mechanical properties of carbide reinforced alumina ceramic tool materials, Ceram. Int. 40 (2014) 2809-2817

108. T. Aiso, U. Wiklund, M. Kubota, S. Jacobson, Effect of Si and $\mathrm{Al}$ additions to carbon steel on material transfer and coating damage mechanism in turning with CVD coated tools, Wear 368-369 (2016) 379-389

109. J. Zhao, X. Ai, X.P. Huang, Relationship between the thermal shock behavior and the cutting performance of a functionally gradient ceramic tool, J. Mater. Process. Technol. 129 (2002) 161-166

110. J. Pfeifer, G. Sáfrán, F. Wéber, V. Zsigmond, O. Koszor, P. Arató, C. Balázsi, Tribology study of silicon nitride-based nanocomposites with carbon additions, Mater. Sci. Forum. 659 (2010) 235-238

111. X. Tian, J. Zhao, Y. Wang, F. Gong, W. Qin, H. Pan, Fabrication and mechanical properties of $\mathrm{Si}_{3} \mathrm{~N}_{4} /(\mathrm{WTi}) \mathrm{C} / \mathrm{Co}$ graded nano-composite ceramic tool materials, Ceram. Int. 41 (2015) 3381-3389

112. J. Song, C. Huang, M. Lv, B. Zou, S. Wang, J. Wang, An effects of $\mathrm{TiC}$ content and melt phase on microstructure and mechanical properties of ternary $\mathrm{TiB}_{2}$-based ceramic cutting tool materials, Mater. Sci. Eng. A. 605 (2014) 137-143

113. G. Zhao, C. Huang, N. He, H. Liu, B. Zou, Microstructure and mechanical properties at room and elevated temperatures of reactively hot pressed $\mathrm{TiB}_{2}$-TiC-SiC composite ceramic tool materials, Ceram. Int. 42 (2016) 5353-5361

114. D. Tiwari, B. Basu, K. Biswas, Simulation of thermal and electric field evolution during spark plasma sintering, Ceram. Int. 35 (2009) 699-708
115. R. Apetz, M.P. Bruggen, Transparent alumina: a lightscattering model, J. Am. Ceram. Soc. 86 (2003) 480-486

116. J.G. Santanach, A. Weibel, C. Estournès, Q. Yang, C. Laurent, A. Peigney, Spark plasma sintering of alumina: study of parameters, formal sintering analysis and hypotheses on the mechanism(s) involved in densification and grain growth, Acta Mater. 59 (2011) 1400-1408

117. A. Knaislová, P. Novák, S. Cygan, L. Jaworska, M. Cabibbo, High-Pressure Spark Plasma Sintering (HP SPS): a promising and reliable method for preparing Ti-Al-Si alloys, Materials 10 (2017) 465

118. R. Licheri, R. Orrù, C. Musa, A.M. Locci, G. Cao, Consolidation via spark plasma sintering of $\mathrm{HfB}_{2} / \mathrm{SiC}$ and $\mathrm{HfB}_{2} / \mathrm{HfC} / \mathrm{SiC}$ composite powders obtained by self-propagating high-temperature synthesis, J. Alloys Compd. 478 (2009) 572-578

119. O. Guillon, J. Gonzalez-Julian, B. Dargatz, T. Kessel, G. Schierning, J. Rathel, M. Herrmann, Field-assisted sintering technology/ spark plasma sintering: mechanisms, materials, and technology developments, Adv. Eng. Mater. 16 (2014) 830-849

120. T.B. Holland, U. Anselmi-Tamburini, D.V. Quach, T.B. Tran, A.K. Mukherjee, Effects of local Joule heating during the field assisted sintering of ionic ceramics, J. Eur. Ceram. Soc. 32 (2012) 3667-3674

121. C. Ramirez, P. Miranzo, M. Belmonte, M.I. Osendi, P. Poza, S.M. Vega-Diaz, M. Terrones, Extraordinary toughening enhancement and flexural strength in $\mathrm{Si}_{3} \mathrm{~N}_{4}$ composites using graphene sheets, J. Eur. Ceram. Soc. 34 (2014) $161-169$

122. M. Mazaheri, D. Mari, Z.R. Hesabi, R. Schaller, G. Fantozzi, Multi-walled carbon nanotube/nanostructured zirconia composites: outstanding mechanical properties in a wide range of temperature, Compos. Sci. Technol. 71 (2011) 939945

123. J. Liu, H. Yan, M.J. Reece, K. Jiang, Toughening of zirconia/alumina composites by the addition of graphene platelets, J. European Ceram. Soc. 32 (2012) 4185-4193

124. H. Kim, M. Kawahara, M. Tokita, Specimen temperature and sinterability of Ni powder by spark plasma sintering, J. Jpn. Soc. Powder Powder Metal. 47 (2000) 887-891

125. P.R. Matli, R. Abdul-Shakoor, A.M.A. Mohamed, M. Gupta, Microwave rapid sintering of Al-metal matrix composites: a review on the effect of reinforcements, Microstruct. Mech. Prop. Metals 6 (2016) 143-162

126. E.A. Levashov, A.S. Mukasyan, A.S. Rogachev, D.V. Shtansky, Self-propagating high-temperature synthesis of advanced materials and coatings, Int. Mat. Rev. 62 (2017) 203-239

127. I. Borovinskaya, A. Gromov, E. Levashov, Y. Maksimov, A. Mukasyan, A. Rogachev, Concise Encyclopedia of SelfPropagating High-Temperature Synthesis 1st Edition, Elsevier Science, Amsterdam, Netherlands, 2017

128. H.C. Yi, J.J. Moore, Self-propagating high-temperature (combusting) synthesis (SHS) of powder-compacted materials, J. Mater. Sci. 25 (1990) 1159-1168

129. S. Vorotilo, A.Y. Potanin, I.V. Iatsyuk, E.A. Levashov, SHS of silicon-based ceramics for the high-temperature applications, Adv. Eng. Mater. 20 (2018) 8

130. S.K. Mishra, L.C. Pathak, Self-propagating high-temperature synthesis (SHS) of advanced high-temperature ceramics, Key Eng. Mater. 395 (2009) 15-38 
131. E.A. Levashov, Yu.S. Pogozhev, D.V. Shtansky, M.I. Petrzhik, Self-propagating high-temperature synthesis of ceramic materials based on the $\mathrm{Mn}+1$ AXn phases in the $\mathrm{Ti}-\mathrm{Cr}-\mathrm{Al}-\mathrm{C}$ system, Russ. J. Non-Ferrous Met. 50 (2009) 151-159

132. O. Keblouti, L. Boulanouar, M.W. Azizi, M.A. Yallese, Effects of coating material and cutting parameters on the surface roughness and cutting forces in dry turning of AISI 52100 steel, Struct. Eng. Mech. 61 (2017) 519-526

133. X. Tian, J. Zhao, J. Zhao, Z. Gong, Y. Dong, Effect of cutting speed on cutting forces and wear mechanisms in high-speed face milling of Inconel 718 with Sialon ceramic tools, Int. J. Adv. Manuf. Technol. 69 (2013) $2669-2678$

134. K.-D. Bouzakis, N. Michailidis, S. Gerardis, G. Katirtzoglou, E. Lili, M. Pappa, R. Cremer, Application of the impact test to predict coated tools' cutting performance in Milling Inconel 718, Adv. Eng. Mater. 10 (2008) 634-639

135. A. Altin, M. Nalbant, A. Taskesen, The effects of cutting speed on tool wear and tool life when machining Inconel 718 with ceramic tools, Mater. Des. 28 (2007) 2518-2522

136. I. Ucun, K. Aslantasx, B. Gokcxe, F. Bedir, Effect of tool coating materials on surface roughness in micromachining of Inconel 718 super alloy, Proc. IMechE. Part B: J. Eng. Manuf. 228 (2014) 1-13

137. B. Wang, Z. Liu, Cutting performance of solid ceramic end milling tools in machining hardened AISI H13 steel, Int. J. Refract. Met. Hard Mater. 55 (2016) 24-32

138. J. Xie, M.J. Luo, K.K. Wu, L.F. Yang, D.H. Li, Experimental study on cutting temperature and cutting force in dry turning of titanium alloy using a non-coated micro-grooved tool, Int. J. Mach. Tools Manuf. 73 (2013) $25-36$

139. F.M. Aneiro, R.T. Coelho, L.C. Brandão, Turning hardened steel using coated carbide at high cutting speeds, J. Braz. Soc. Mech. Sci. Eng. 30 (2008) 104-109

140. F.F. Lima, W.F. Sales, E.S. Costa, F.J. Silva, A.A. Machado, Wear of ceramic tools when machining Inconel 751 using argon and oxygen as lubri-cooling atmospheres, Ceram. Int. 43 (2017) 677-685
141. Z. Yin, C. Huang, J. Yuan, B. Zou, H. Liu, H. Zhu, Cutting performance and life prediction of an $\mathrm{Al}_{2} \mathrm{O}_{3} / \mathrm{TiC}$ micronano-composite ceramic tool when machining austenitic stainless steel, Ceram. Int. 41 (2015) 7059-7065

142. D. Jianxin, S. Wenlong, Z. Hui, Y. Pei, L. Aihua, Friction and wear behaviors of the carbide tools embedded with solid lubricants in sliding wear tests and in dry cutting processes, Wear 270 (2011) 666-674

143. T. Sugihara, H. Tanaka, T. Enomoto, Development of novel CBN cutting tool for high speed machining of Inconel 718 focusing on coolant behaviors, Proc. Manuf. 10 (2017) 436442

144. T.F. Ariff, N.S. Shafie, Z.M. Zahir, Wear analysis of silicon nitride $\left(\mathrm{Si}_{3} \mathrm{~N}_{4}\right)$ cutting tool in dry machining of T6061 aluminum alloy, Appl. Mech. Mater. 268-270 (2013) 563567

145. S.B. Dhage, P. Sarkar, A.D. Jayal, Investigation of surface textured cutting tools for sustainable machining, 5th Int. \& 26th All India Manuf. Technol., Des. Res. Conference (AIMTDR) 2014, IIT Guwahati, Assam, India

146. T. Baksa, T. Kroupa, P. Hanzl, M. Zetek, Durability of cutting tools during machining of very hard and solid materials, Proc. Eng. 100 (2015) 1414-1423

147. W. Shizhu, H. Ping, Principles of Tribology, John Wiley \& Sons (Asia) Pte Ltd, 1 Fusionopolis Walk, Solaris South Tower, Singa, 2012

148. I. Korkut, M. Boy, Experimental examination of main cutting force and surface roughness depending on cutting parameters, Strojniški vestnik - J. Mech. Eng. 54 (2008) $531-538$

149. Y. Ma, P. Feng, J. Zhang, Z. Wu, D. Yu, Prediction of surface residual stress after end milling based on cutting force and temperature, J. Mater. Process. Technol. 235 (2016) 41-48

150. A.A. Vereschaka, A.D. Batako, A.A. Krapostin, N.N. Sitnikov, G.V. Oganyan, Improvement in reliability of ceramic cutting tool using a damping system and nanostructured multi-layered composite coatings, Proc. CIRP 63 (2017) 563-568

Cite this article as: Sergey N. Grigoriev, Sergey V. Fedorov, Khaled Hamdy, Materials, properties, manufacturing methods and cutting performance of innovative ceramic cutting tools - a review, Manufacturing Rev. 6, 19 (2019) 